Research Article

\title{
Experimental Research on the Transverse Effective Bending Rigidity of Shield Tunnels
}

\author{
Gang Zheng, ${ }^{1,2}$ Yawei Lei $\mathbb{D}^{2},{ }^{2}$ Tao Cui, ${ }^{2,3}$ Xuesong Cheng $\mathbb{D}^{1,2}$ Yu Diao ${ }^{1},{ }^{1,2}$ Tianqi Zhang, \\ and Jibin Sun ${ }^{2}$ \\ ${ }^{1}$ MOE Key Laboratory of Coast Civil Structure Safety, Tianjin University, Tianjin 300072, China \\ ${ }^{2}$ Department of Civil Engineering, Tianjin University, Tianjin 300072, China \\ ${ }^{3}$ China Railway Design Corporation, Tianjin 300142, China
}

Correspondence should be addressed to Xuesong Cheng; cheng_xuesong@163.com

Received 12 July 2019; Revised 3 September 2019; Accepted 16 September 2019; Published 4 November 2019

Academic Editor: Jian Ji

Copyright (c) 2019 Gang Zheng et al. This is an open access article distributed under the Creative Commons Attribution License, which permits unrestricted use, distribution, and reproduction in any medium, provided the original work is properly cited.

The uniform rigidity ring model is commonly used to design the segmented structures of shield tunnels. However, model tests have been primarily used to study the transverse effective rigidity ratio $\eta$ with a concentrated force, which is notably different from realistic loading patterns. To obtain more reasonable $\eta$ values, in this study, tests were performed with a concentrated load on an experimental bench and with a realistic loading pattern in sandy soil in a rigid steel tank. Three types of segmental ring models were designed and tested: straight-jointed, stagger-jointed, and uniform rings. The test results indicated that the $\eta$ values of the stagger-jointed assembly mode were clearly larger than those of the straight-jointed assembly mode under both loading patterns. $\eta$ increased as the load increased under the realistic loading conditions, whereas $\eta$ decreased as the load increased under the concentrated load. More importantly, the $\eta$ values derived from the realistic load tests were considerably larger than those derived from the concentrated load tests for both assembly modes (i.e., $0.423-0.672$ and $0.587-0.761$ for the straight-jointed and staggerjointed assembly modes, respectively), and the former should be recommended for practical engineering applications. Furthermore, formulas relating $\eta$ to the ratio of the cover depth to the tunnel diameter were proposed for sandy soil.

\section{Introduction}

The shield tunnelling approach is less expensive than other tunnelling methods and has little influence on the environment; hence, a substantial number of urban underground tunnels have adopted this new construction technique $[1,2]$. Most shield-driven tunnels have employed precast concrete linings with jointed segments connected by steel bolts. Therefore, the influences of the joints on the internal forces and the deformations of the linings are considered when designing the tunnel lining [3]. For most current design methods, loads that are applied to the lining structure should be considered first, and the other parameters of the segments can then be calculated via structural analysis. Therefore, it is essential to select a suitable design method to determine the internal forces and segment interactions [4, 5]. In 1978, the International Tunnelling
Association (ITA) combined and summarised the design methods utilised in different countries [2, 6, 7]. Lee et al. [1] classified the common design methods into four primary categories: experiential design approaches, testing design methods, elastic foundation approaches, and continuum mechanics models.

The elastic foundation approach is the most frequently utilised design method because of its conciseness and convenience. In addition, this method can classify the types of joints of segments using the universal rigidity ring method $[8,9]$, the average uniform rigidity ring method $[10-13]$, the multihinge ring method [14], and the beam-spring model method [15-17]. Structural models that correspond to these approaches are illustrated in Figure 1 [18].

Every design method has its own engineering applications. The simplest design method is the uniform rigidity ring method; however, this method always overestimates the 


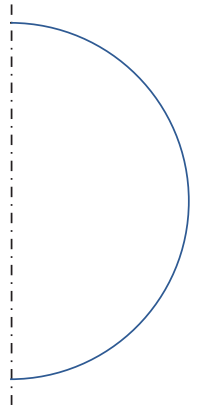

(a)

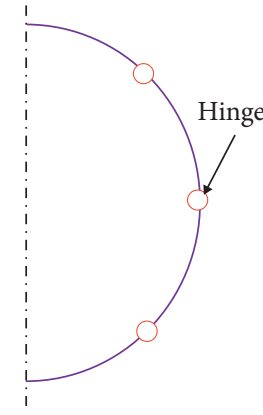

(b)

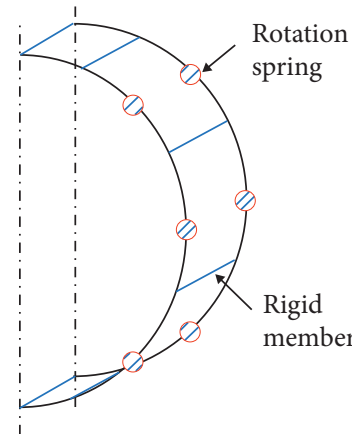

(c)

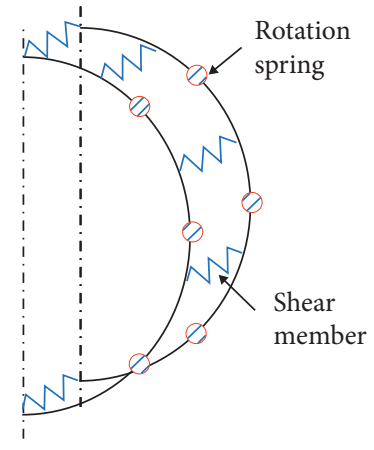

(d)

Figure 1: Types of segmented joints (Koyama [18]). (a) Uniform rigid ring. (b) Multihinge ring. (c) Beam spring (I). (d) Beam spring (II).

service life of a joint, which may create risks. In the multihinge ring approach, the surrounding pressure and soil resistance have substantial impacts on the stress and deformation of the linings. This model is applicable only to hard strata and straight-jointed assembly patterns, and it may lead to a small bending moment. The beam-spring model method appears to be the most sophisticated approach, and it is generally applicable for evaluating the influence of joint stiffness on the mechanical properties of segmental rings under different ground conditions. However, the calculation in this method is relatively complicated.

Currently, the segmented structural design of a shield tunnel always takes advantage of the average uniform rigidity ring method due to its clear concept and simple calculation. However, the value of $\eta$ (the transverse bending rigidity ratio) is essential because the maximum bending moment of the segments and the convergence deformation of the diameter are closely associated with the effective rigidity $\eta \mathrm{EI}$ (the flexural bending rigidity) [19]. To date, the value and influence of $\eta$ have been studied by several researchers, using different methods, such as theoretical analyses and model tests.

Muir Wood [11] used a theoretical analysis to derive a calculation method for the value of $\eta$ that considers the effects of the joint stiffness and the number of segments. Liu and Hou [15] developed an equation for the value of $\eta$ by reducing the stiffness of the segment joints and compared it with the continuous ring method.

Lee and Ge [20] also proposed a formula for $\eta$ that is expressed by several parameters for a straight-jointed ring, and the formula includes the stiffness ratio of the joint. Their research recommended that $\eta$ should generally be between 0.1 and 0.6 for soft ground. By comparing the maximum horizontal displacements calculated by the uniform rigidity ring approach and the beam-spring model, Zhong et al. [21] suggested that $\eta$ should generally range from 0.4 to 0.8 . In the engineering field, the theoretical analysis approach is relatively complex and can counteract the conciseness and convenience of the uniform rigidity ring method.

For prototype loading tests, Japanese standards [19] recommend values of $\eta$ and $\zeta$ (the additional rate of bending moment) of 0.8 and 0.3 , respectively, and a value of $\eta$ of 0.8 was adopted for the design of a shield tunnel in Tokyo [22].
In addition, Kashima et al. [23] performed prototype loading tests on the stagger-jointed mode of the DPLEX shield tunnel and determined that an $\eta$ value of 0.8 was meaningful. Feng et al. [24] also performed prototype tests to analyse the sensitivity factors of $\eta$ and $\zeta$; they found that the value of $\eta$ increased with an increase in the profile of the shield tunnel and that the value of $\zeta$ decreased with an increase in the profile.

Using model tests, $\mathrm{Xu}$ [25] and Huang et al. [26] reported that the values of $\eta$ were 0.67 and 0.75 in straightjointed and stagger-jointed modes, respectively. In their tests, the tunnel segments were composed of polyethylene $(\mathrm{PE})$, and the joints were simulated by PE sheets connecting the segments on the surface without considering the true structure of the joint. Ye et al. [4] conducted segmental ring loading model tests under a concentrated load and used polymethylmethacrylate and aluminium welding wire to simulate the segment and bolt, respectively. They concluded that the values of $\eta$ were $0.09-0.23$ and $0.3-0.8$ under the straight-jointed assembly mode and stagger-jointed assembly mode, respectively. In these model tests, the outside diameter of the prototype tunnel was 6.2 metres, which is a typical size for subway tunnels in China, and the joints were connected with curving bolts.

Currently, concentrated loads are always used in model tests $[4,25,26]$. The loads applied to the shield lining are similar to the pattern shown in Figure 2 [1, 13, 19]. In addition to the lining thickness and joint stiffness, the strata resistance and the loading conditions can also significantly influence the value of $\eta$ [20]. Ye et al. [4] noted that the realistic $\eta$ value of a segmental ring in a model test is affected by the surrounding soil. Therefore, using a realistic loading pattern in a model test to study the $\eta$ values is important.

In this paper, the relationships between segments and joints were determined in detail using similarity theory, and a new similarity method that considers the deformation characteristics of the joint was used. Based on the similarity relationships, the segmental tunnel models were further processed to perform model tests; the model segments were simulated using polypropylene (PP), and the model bolts were simulated using an aluminium wire. Similar to several previous studies, the model tests were first performed under the concentrated load given in the experimental standard. In 


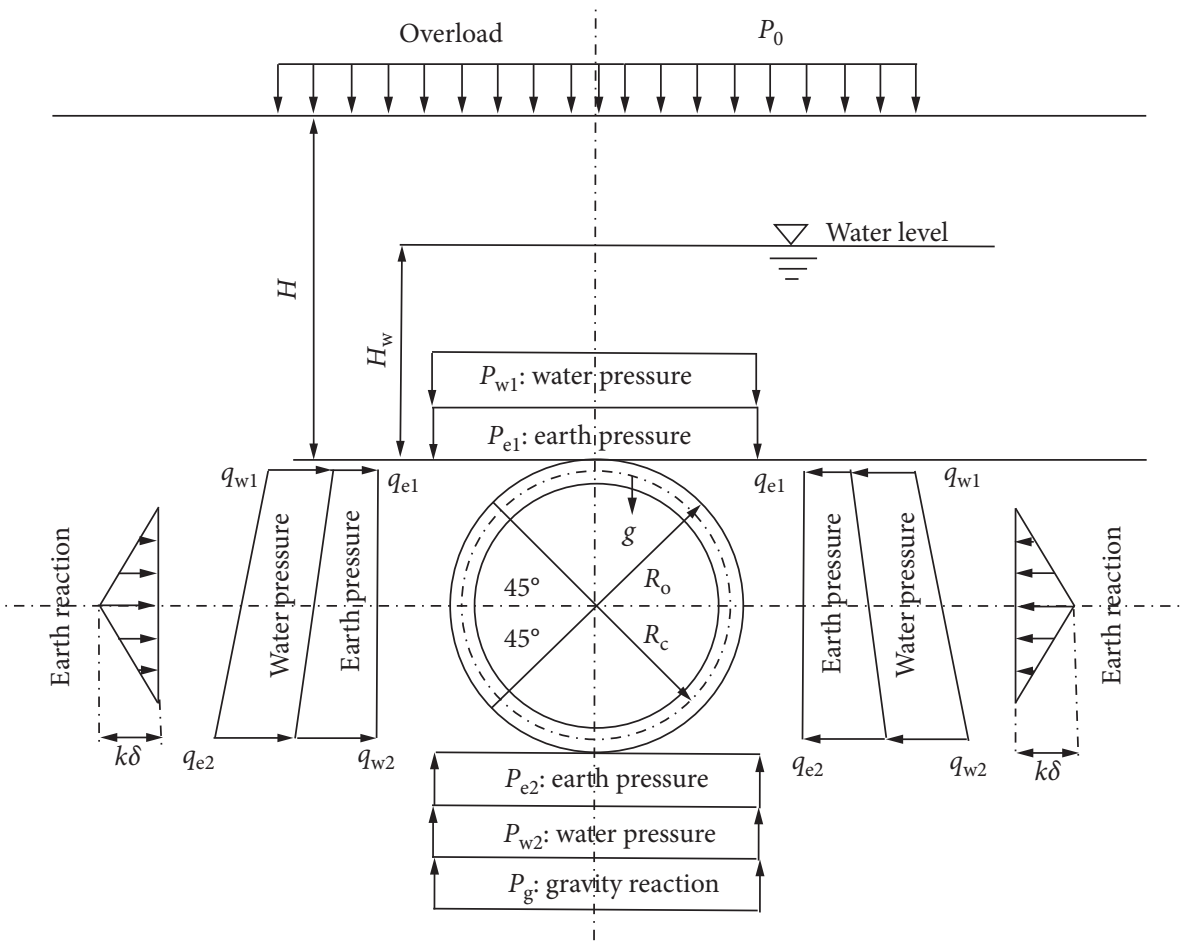

FIGURE 2: Loads in a conventional model (JSCE [19]).

addition, to determine more reasonable values for $\eta$, model tests were performed with a realistic loading pattern in sandy soil using homemade loading devices in a rigid steel tank. Based on the test results, the $\eta$ values for different segmental ring models were analysed and compared with previous studies, and formulas relating the $\eta$ value to the $C / D$ ratio (ratio of the cover depth to the tunnel diameter) were proposed for sandy soil.

\section{Design of the Model Test}

2.1. Similarity Relationships. The theorems that form the basis of similarity theory have three common points that can guide the design of the model test and the processing of test data [27-34]. The similarity analysis includes the similarity relationships of the segment and the joint.

2.1.1. Similarity Relationships of the Segment. The selfweight of the segment is much smaller than the concentrated force in the concentrated loading pattern and the overburden pressure in the realistic loading pattern; thus, model tests typically do not consider the weight of the segment. When a model segment and a prototype segment have similar behaviour, the similarity relationships should be satisfied in terms of the size, material properties, external load, and static response of the segment. The similarity relationships of the segment are expressed below, where the subscripts $p$ and $m$ represent the prototype and the model, respectively. Similarity relationships of the segment are demonstrated in Table 1.

The length $L$ and the elastic modulus $E_{s}$ can be determined from the basic dimensions. In terms of $\pi$ theorem
$[35,36]$, the similarity relationships of the variables are as follows:

$$
\begin{aligned}
& C_{\delta}=C_{L}, \\
& C_{\sigma}=C_{q}=C_{E_{s}}, \\
& C_{\varepsilon}=C_{\theta}=C_{v}=1, \\
& C_{F}=C_{E_{s}} C_{L}^{2} .
\end{aligned}
$$

2.1.2. Similarity Relationships of the Joint. $\mathrm{Xu}$ [25] and Huang et al. [26] considered the bolts (modelled by a PE sheet) to be springs, and the similarity of the total elastic stiffness coefficient $K_{1}$ of the joints was considered in their tests. The total elastic stiffness coefficient $K_{1}$ can be calculated as follows:

$$
K_{1}=N \frac{E_{1} A_{1}}{l_{1}}
$$

where $N$ represents the total number of longitudinal and circumferential joints and $E_{1}, A_{1}$, and $l_{1}$ represent the elastic modulus, cross-sectional area, and length of the joint (PE sheet), respectively. Xu [25] and Huang et al. [26] considered the bolts to be springs and did not consider the structure of the joint. As a result, the common points of the relationship of the joint were not meaningful.

Considering the joint design process, Ye et al. [4] reported that the similarity relationships for the size and material properties of the bolt should be satisfied. The geometric scale ratio can be obtained from the similarity relationships of the segment, and the elastic modulus $E_{b}$ can 
TABLE 1: Similarity relationships of the segment.

\begin{tabular}{lcr}
\hline Category of scale ratio & Physical quantities & Similarity relationships \\
\hline & Diameter of the segmental lining $(D)$ & $C_{L}=D_{p} / D_{m}$ \\
Geometric scale ratio $C_{L}$ & Thickness of the segment $(t)$ & $C_{L}=t_{p} / t_{m}$ \\
& Breadth of the segment $(b)$ & $C_{L}=b_{p} / b_{m}$ \\
Geometric scale ratio $\left(C_{E_{s}}\right.$ and $\left.C_{v}\right)$ & Elastic modulus of the segment $\left(E_{s}\right)$ & $C_{E_{s}}=\left(E_{s}\right)_{p} /\left(E_{s}\right)_{m}$ \\
& Poisson's ratio of the segment $\left(v_{s}\right)$ & $C_{v}=\left(v_{s}\right)_{p} /\left(v_{s}\right)_{m}$ \\
External load $\left(C_{F}\right.$ and $\left.C_{q}\right)$ & Concentrated force acting on segment $(F)$ & $C_{F}=\left(F_{s}\right)_{p} /\left(F_{s}\right)_{m}$ \\
& Realistic soil load acting on segment $(q)$ & $C_{q}=\left(q_{s}\right)_{p} /\left(q_{s}\right)_{m}$ \\
& Stress of segment $\left(\sigma_{s}\right)$ & $C_{\sigma}=\left(\sigma_{s}\right)_{p} /\left(\sigma_{s}\right)_{m}$ \\
Static response $\left(C_{\sigma}, C_{\varepsilon}, C_{\delta}\right.$, and $\left.C_{\theta}\right)$ & Strain of segment $\left(\varepsilon_{s}\right)$ & $C_{\varepsilon}=\left(\varepsilon_{s}\right)_{p} /\left(\varepsilon_{s}\right)_{m}$ \\
& Deformation of segment $\left(\delta_{s}\right)$ & $C_{\delta}=\left(\delta_{s}\right)_{p} /\left(\delta_{s}\right)_{m}$ \\
& Rotation angle of segment $\left(\theta_{s}\right)$ & $C_{\theta}=\left(\theta_{s}\right)_{p} /\left(\theta_{s}\right)_{m}$ \\
\hline
\end{tabular}

be obtained from the bending rigidity ratio and the compressive (or extensional) rigidity ratio of the prototype tunnel. The expressions for the circumferential joints can be expressed as follows:

$$
\begin{aligned}
& \frac{\left(E_{s} \cdot I_{s}\right)_{p}}{\left(n \cdot E_{b} \cdot I_{b}\right)_{p}}=\frac{\left(E_{s} \cdot I_{s}\right)_{m}}{\left(n^{\prime} \cdot E_{b} \cdot I_{b}\right)_{m}}=\alpha_{1}, \\
& \frac{\left(E_{s} \cdot A_{s}\right)_{p}}{\left(n \cdot E_{b} \cdot A_{b}\right)_{p}}=\frac{\left(E_{s} \cdot A_{s}\right)_{m}}{\left(n^{\prime} \cdot E_{b} \cdot A_{b}\right)_{m}}=\alpha_{2},
\end{aligned}
$$

where $I_{s}=b t^{3} / 12, I_{b}=\pi d^{4} / 64, A_{s}=(\pi / 4)\left(D^{2}-(D-2 t)^{2}\right)$, $A_{b}=\pi d^{2} / 4$, and $n$ and $n^{\prime}$ are the numbers of transverse bolts in the prototype and the model tunnel, respectively, $d$ is the diameter of the bolt, $\alpha_{1}$ is the bending rigidity ratio of the segment and the joint bolt, and $\alpha_{2}$ is the compressive (or extensional) rigidity ratio.

In fact, the bolt in the joint experiences tension, and the concrete in the joint is under pressure. Hence, the conclusion that the bolt is subjected to a bending moment is incorrect. Ye et al. [4] and Huang et al. [26] improved the method to consider the deformation features of a joint when a load was applied to the joint. Zheng et al. [37] proposed the formula for the additional deformation $\Delta l_{b}$ of the bolt and the relative rotation angle $\theta$ of two adjacent segments, and they deduced the similarity relationships between the prototype and the model bolt, which are expressed as follows:

$$
\left(\frac{n \cdot E_{b} \cdot A_{b}}{l_{b}}\right)_{p}=\left(\frac{n^{\prime} \cdot E_{b} \cdot A_{b}}{l_{b}}\right)_{m} \cdot C_{E_{s}} \cdot C_{L} .
$$

Thus, equation (4) can be expressed as $\left(n \cdot E_{b} \cdot A_{b}\right)_{p}=\left(n^{\prime} \cdot E_{b} \cdot A_{b}\right)_{m} \cdot C_{E_{s}} \cdot C_{L}^{2}$. This finding indicates that when $\left(l_{b}\right)_{p} /\left(l_{b}\right)_{m}=C_{L}$, equation (4) is equivalent to equation (5). However, equation (4) limits the determination of the cross-sectional area and length of the bolt in the model tunnel, which can lead to difficulty when choosing different types of fibres for the model test. In addition, the similarity relations of the longitudinal joints can be determined from equation (5).

Based on the geometric scale ratio $C_{L}$ and material property ratio $C_{E_{s}}$, the relational expression between the geometric dimension and $E_{b}$ in the model can be determined using equation (5). In the next section, the materials and the geometric aspects of the bolt are determined.

2.2. Material Selection. The segments and joints of a typical subway tunnel in China always use C50 reinforced concrete and M30 steel bolts (Zhang and Huang [38]), and the model segments and joints simulate this kind of a subway tunnel. The materials of the segment and the joint were selected based on tensile tests.

2.2.1. Segment Selection. Model segments adopt materials such as PE [25, 26], polyvinyl chloride (PVC) [39], polymethylmethacrylate (PMMA) [4], and aluminium alloy [40]. Material selection is essential in model testing; selection of an appropriate material is a prerequisite for a successful model test. Ye et al. [4] performed tensile tests on PMMA, nylon, polyoxymethylene (POM), and acrylonitrile butadiene styrene (ABS). In this paper, PMMA, POM, and PP were selected to create the model segments, and the tensile strengths and elastic moduli of these materials were acquired from tensile experiments. The tensile strengths of PMMA, POM, and PP were 64.2 MPa, 29.95 MPa, and $30.67 \mathrm{MPa}$, respectively. The elastic moduli of them were $3.48 \mathrm{GPa}$, $1.69 \mathrm{GPa}$, and $3.22 \mathrm{GPa}$, respectively.

The geometric scale ratio $C_{L}$ was set to 20 in each model test. The model tests were performed with homemade loading devices. The test procedure included a concentrated loading pattern on an experimental bench and a realistic loading pattern in sandy soil. For the realistic loading pattern, the average unit weight of the soil was nearly equal to that of the prototype and the model under $1 \mathrm{~g}$ conditions. The distributed load $q$ acting on the segment was in proportion to the thickness of the overlying soil. Thus, the stress constant $C_{\sigma}$ in the soil was consistent with the thickness constant $C_{L}$ of the overlying soil, i.e., $C_{\sigma}=C_{L}$. To ensure that the similarity constants were consistent in the soil and the segment, the elastic modulus similarity constant $C_{E_{s}}$ should be set to 20 due to the geometric similarity constant $C_{L}=20$. The values of $E_{s}$ of the concrete in the prototype and the values of $E_{s}$ of the PP in the model tests were $34.50 \mathrm{GPa}$ and $1.69 \mathrm{GPa}$, respectively, which led to $C_{E_{s}}=34.5 / 1.69=20.4$. 
Consequently, PP was a reasonable model material for simulating the prototype segment.

2.2.2. Bolt Selection. The type of model bolt must satisfy the segment assembly requirements and the geometric and elastic modulus similarities. Considering the results of the bolt tension tests in Zheng et al. [37] and based on the elastic modulus similarity constant $C_{E_{s}}=20.4$ and the geometric similarity constant $C_{L}=20$, the value of $\left(E_{b} \cdot A_{b} / l_{b}\right)_{m}$ can be calculated using equation (5): $\left(E_{b} \cdot A_{b} / l_{b}\right)_{m}=3.711 \times$ $10^{8} \mathrm{~N} / \mathrm{m}$. We decided that an aluminium wire (type 1060) was suitable for a secondary processing material and had a small size that fit the size of the segment. Therefore, the aluminium wire was selected to manufacture the model bolts, and the elastic modulus, length, and diameter of the model circumferential bolt were $31.68 \mathrm{GPa}, 0.026 \mathrm{~m}$, and $0.001 \mathrm{~m}$, respectively. Furthermore, the length and diameter of the model longitudinal bolt were $0.033 \mathrm{~m}$ and $0.0016 \mathrm{~m}$. In addition, the model used 12 circumferential bolts and 8 longitudinal bolts.

2.3. Model Fabrication. Due to the geometric similarity ratio $C_{L}=20$, the size of the model tunnel was not exactly the same as that of the prototype tunnel. Several adjustments were made to the model design: (1) To ease the assembly of the ring, the circumferential bolts used straight aluminium wires, even though curved bolts are often adopted in prototype segments, as shown in Figure 3(a). To reduce the number of slots, curved bolts were selected to fabricate the longitudinal bolts, as shown in Figure 3(b). This approach can reduce the cross section of the segment, and the longitudinal bolts can remain consistent in the actual case by applying pretightening forces, as shown in Figure 3(b). (2) To make it easy to install the bolts for the circumferential joints, the circumferential bolt holes were set outside of the segment at the designated location where the circumferential bolt's location was not transformed. (3) For simplicity, the pretightening forces applied to the circumferential bolts did not follow the similarity relation with the prototype, and watertight strips and concave-convex faces at the joints were not used in the model segment joints. These adjustments had little influence on the structural stress and deformation. Detailed drawings of the circumferential and longitudinal bolts are shown in Figure 3, and the three types of segment joints, i.e., straight-jointed, stagger-jointed, and uniform rings, are shown in Figure 4.

2.3.1. Segment Fabrication. The model segment used an intact PP pipe; the length, outer diameter, and thickness of the pipe were $3000 \mathrm{~mm}, 310 \mathrm{~mm}$, and $17.5 \mathrm{~mm}$, respectively. The PP pipe was cut into standard segments, adjacent segments, and top segments, as shown in Figure 3. The segments were then polished to ensure a good surface that met the design requirements. Finally, the segments were punched and chiselled so that the bolt holes and slots were in accordance with the bolt distribution and dimensions, as shown in Figures 3-4.

\subsubsection{Bolt Fabrication}

(1) Longitudinal Bolts. The diameter and length of the model bolt were $1.6 \mathrm{~mm}$ and $33 \mathrm{~mm}$, respectively. First, one end of the longitudinal bolt was fixed by an aluminium cap, and the opposite end was fixed by a fixator once the pretightening force of the bolt was reached (approximately $25 \mathrm{~N}$ in the model) [41]. The pretightening force was measured with a dynamometer.

(2) Circumferential Bolts. Because the diameter of the model bolt was only $1 \mathrm{~mm}$, it was difficult to form a bolt with the aluminium wire (type 1060). As a result, the aluminium wire (type 1060) with a diameter of $2 \mathrm{~mm}$ was used. First, the aluminium wire was cut to the bolt's design length, and threads were made at both ends of the bolt. Finally, the middle section was polished to reduce the diameter to $1 \mathrm{~mm}$, as shown in Figure 3.

2.3.3. Model Assembly. The model segments and bolts were assembled into three types of rings, i.e., the straight-jointed assembly mode, the stagger-jointed assembly mode, and the uniform assembly mode, as shown in Figure 4. Three rings and eighteen rings were combined for the concentrated loading pattern on the experimental bench and the realistic loading pattern in the sandy soil, respectively.

\section{Experimental Setup and Testing Procedure}

Many experiments were performed under the concentrated loading pattern and the realistic loading conditions. Detailed descriptions of the test devices and the experimental procedures for the two loading patterns are presented below.

\subsection{Concentrated Loading Pattern on the Experimental Bench}

3.1.1. Experimental Bench. For the concentrated loading pattern, the tunnel model was packed in a vault position on the experimental bench, as shown in Figure 5. The top of the bench was formed into a round arc to ensure that the tunnel model remained stable during the loading process. An iron plate was attached to the vault of the tunnel model, and several weights were placed on the plate.

3.1.2. Instrumentation. Mechanical digital micrometers were used to determine the variations in movement of the segmental ring. Three rings were used in each type of the segmental ring model in each test, and the middle ring was the focus, as shown in Figure 5. Seven radial displacement monitoring points were arranged every $45^{\circ}$ around the circumference, as shown in Figure 5, and the radial movements of the monitoring points on the middle ring were recorded.

3.1.3. Testing Procedure. The goal of the model tests was to determine the $\eta$ values. The loading in each test consisted of 


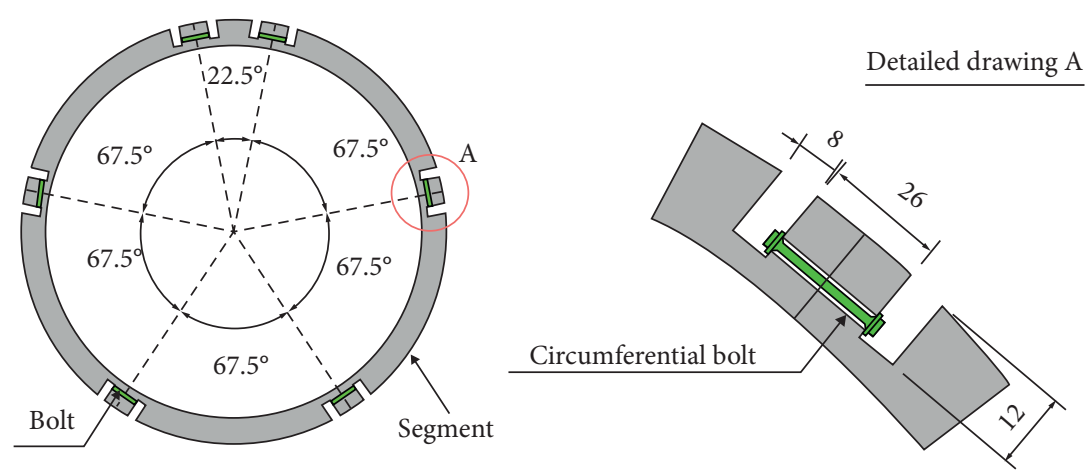

(a)
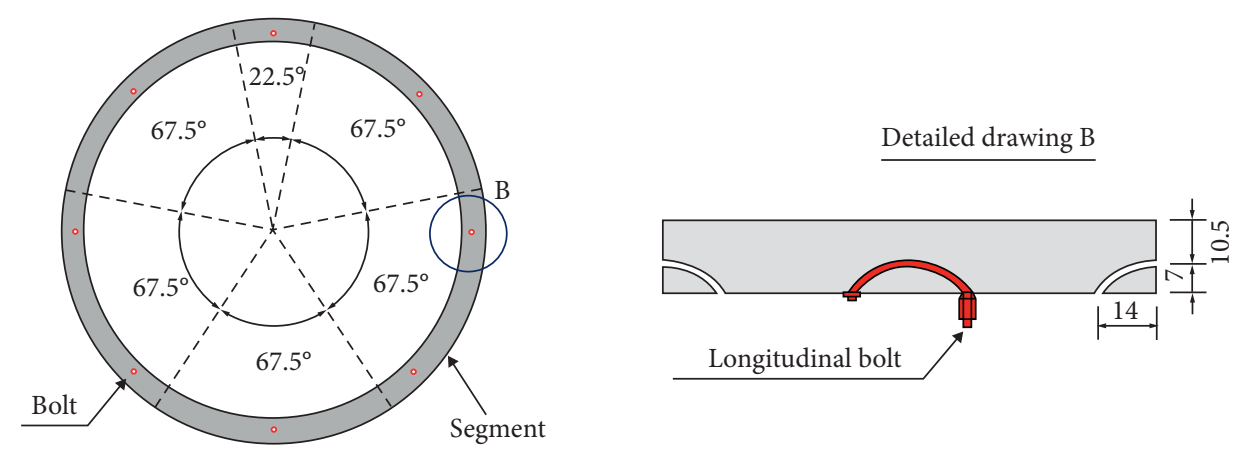

(b)

FIgURE 3: Distributions of (a) circumferential bolts and (b) longitudinal bolts (unit: $\mathrm{mm}$ ).

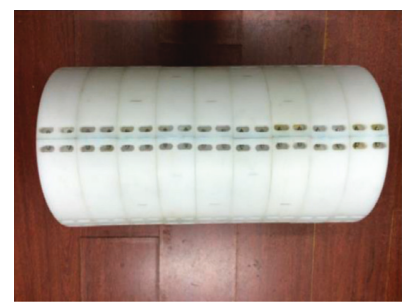

(a)

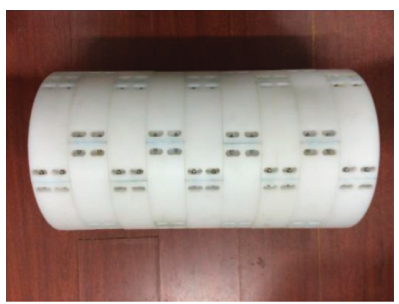

(b)

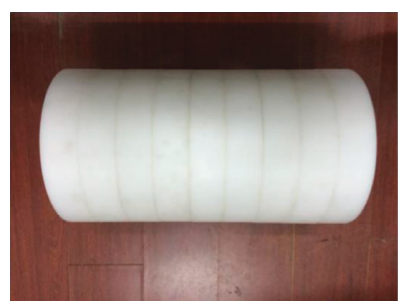

(c)

Figure 4: Photographs of the three types of ring models. (a) Straight-jointed ring. (b) Stagger-jointed ring. (c) Uniform ring.

ten stages, and the load was $5.1 \mathrm{~kg}$. The loading procedure was as follows:

(1) Paste the iron plate to the vault

(2) Add one weight $(5.1 \mathrm{~kg})$ to the plate

(3) Repeat the second step until ten loading stages have been completed

The loading experiment was conducted three times for each type of the segmental ring model. The results are summarised and analysed in Section 4.1.

\subsection{Realistic Loading Pattern in Sandy Soil}

3.2.1. Model Box. The model tank was the same as the other tank. The rigid steel tank was $1800 \mathrm{~mm}$ wide, $1900 \mathrm{~mm}$ high, and $1080 \mathrm{~mm}$ thick, and it contained two $20 \mathrm{~mm}$ plexiglass windows [37], as illustrated in Figure 6.
The model tunnel was laid horizontally in the middle of the model box. The minimum distance between the tunnel and the inner walls of the model box was 2.4 times the diameter of the tunnel, which reduced the impact of the rigid boundaries on the deformation of the tunnel. The distance between the inner tank's bottom and the tunnel invert was $2.0 D$ (i.e., $620 \mathrm{~mm}$ ), and the rigid bottom can be considered to be the bedrock of the sandy layer.

3.2.2. Instrumentation. Complementary metal-oxide-semiconductor (CMOS) laser displacement sensors and a DH3820 static data collection gauge were used to determine the displacements of the segmental ring model. The laser displacement sensors were placed on the central horizontal shaft of the tunnel. Measurements were taken prior to testing to determine the large displacements of the typical monitoring points on the ninth ring. 


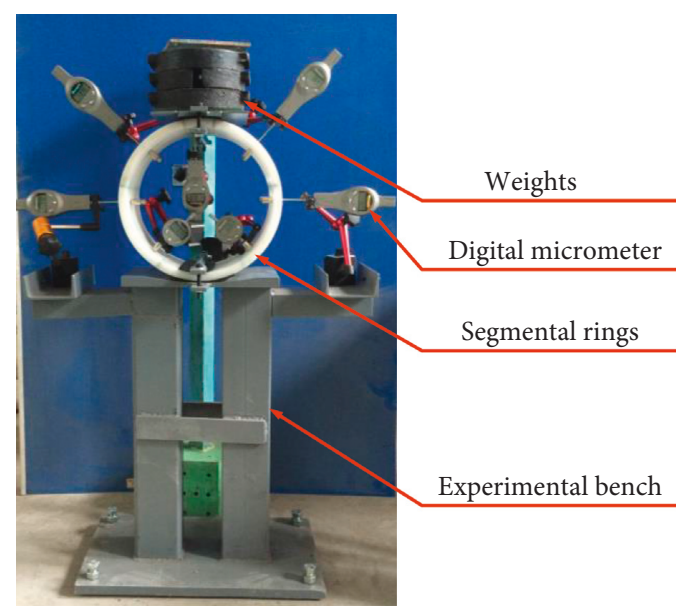

(a)

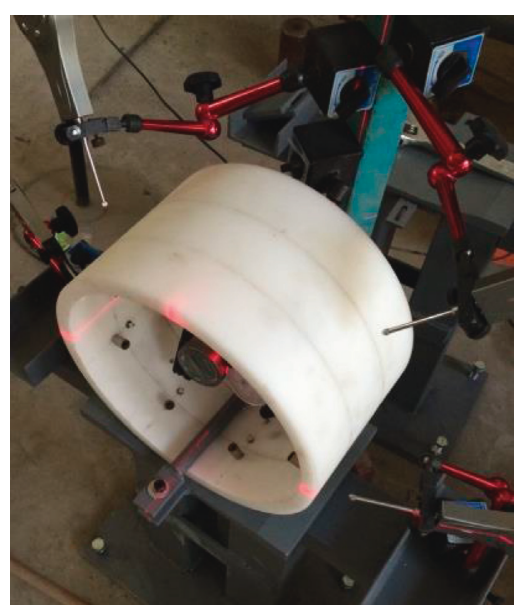

(b)

FIgURE 5: Concentrated loading pattern on the experimental bench. (a) Front view. (b) Top view.

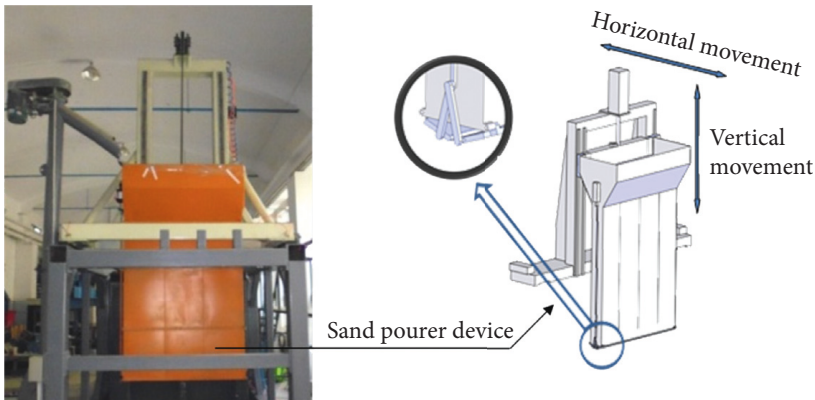

(a)

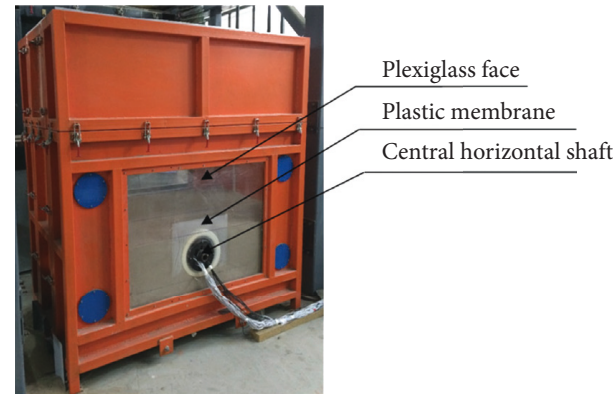

(b)

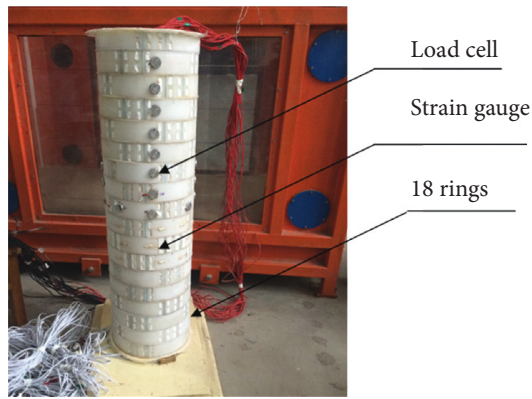

(c)

Figure 6: Testing devices. (a) Sand pourer device. (b) Strong box. (c) Model tunnel.

To obtain the earth pressure distribution in each test, the lining was installed with twenty-six sensors connected to the DH3820 static data collection gauge. The sensors (load cells) had an accuracy of $\pm 0.02 \%$, and the diameter of the sensing surface was $25 \mathrm{~mm}$.

The eight radial sensors around the circumference were equally arranged at $45^{\circ}$ angles on the tenth ring from the vault, and the remaining sensors were placed at the vaults from the tenth to the seventeenth rings, as shown in Figure 6.

To determine the precise pressures from the load cells, pressure loading calibration tests were performed, and the results of the calibration tests showed that a linear relationship existed between the pressure of the load cell and the depth of water.
3.2.3. Fine Sand. Dry fine sand was used for the model test; the sand was the same as that used by Zheng et al. [37]. The falling height was kept at $300 \mathrm{~mm}$ above the soil surface prior to testing. The density, void ratio, and critical state friction angle of the sand were $1550 \mathrm{~kg} / \mathrm{m}^{3}, 0.67$, and $30.96^{\circ}$, respectively.

3.2.4. Testing Procedure. A testing process was used to ensure that the conditions of the sand (e.g., void ratio) remained consistent during the series of experiments for the three types of segmental ring models. At the beginning of the test, the position of the tunnel model was pinned on the plexiglass faces. During the tests, the soil pressures were 
recorded, and the results of the three types of segmental ring models were compared to illustrate the differences in the external forces on the tunnel. The specific testing procedure is described as follows:

(1) From the bottom of the model box to the model tunnel invert, the soil was divided into three layers with thicknesses of $200 \mathrm{~mm}, 200 \mathrm{~mm}$, and $220 \mathrm{~mm}$. For each layer, the sand was rained to the design depth, and the surface of the sand layer was tamped with a steel plate. After tamping the last sand layer, additional sand was poured onto the upper surface of the layer and tamped; this procedure continued until the sand reached the level of the tunnel invert.

(2) After the end of the sand preparation procedure, the model tunnel was installed at the design depth, and the ends of the tunnel were wrapped with plastic membranes packed against the plexiglass face.

(3) The sand around the tunnel was gently pushed to ensure good contact with the surface of the model tunnel. The monitoring equipment was then turned on to monitor the earth pressure and the nonmovement of the representative positions.

(4) Another layer of sand was rained onto the top of the tunnel vault; this layer was $155 \mathrm{~mm}$ thick (approximately $0.5 D$ ). After this layer was complete, all sensors remained stable and recorded for ten minutes before moving to the next step.

(5) On the top of the tunnel vault, the thickness of each layer was $0.5 D(155 \mathrm{~mm})$. The final height above the crown was $4 D(1240 \mathrm{~mm})$ and was attained by repeating the fourth step.

Similar to the concentrated loading pattern, the experiment was performed and repeated three times for each type of the segmental ring model. The results are summarised and analysed in Section 4.2.

\section{Experimental Results and Analysis}

Model tests were performed with two loading patterns, and the measured results of the model tests are summarised and discussed. For further analysis, the $\eta$ values of the segmental ring models were recorded and compared with those in previous studies, and the range of $\eta$ values was used for practical engineering applications.

4.1. Concentrated Loading Pattern on the Experimental Bench. The results of the nine tests under the concentrated loading conditions (three tests for each assembly mode) reflected the deformation features of the three types of ring models, as shown in Figure 7. The variations in the vertical and horizontal diameters of the middle ring are discussed below.

4.1.1. Transverse Deformation Characteristics under the Concentrated Loading Conditions. The results indicate that the three tests for each mode provided similar results, which indicates the repeatability of the test results. In Figure 7 and the other figures, positive values of the changes in diameter indicate that the tunnel diameters increased with increasing load, which was the case for the horizontal diameter variations; in contrast, negative values indicate that the tunnel diameter decreased.

The average diameter variation is the result of the three repeated tests for each assembly mode, and the results are presented in Figure 8. As the load increases, the variations in the diameters (absolute values) increase linearly during the entire loading process; however, the slopes are different for the horizontal and vertical diameters. In addition, the significantly different slopes for the different assembly modes indicate that the type of the assembly mode had a major influence on the transverse deformation characteristics of the model tunnel.

4.1.2. The Value of $\eta$ under the Concentrated Loading Conditions. According to Lee and Ge [20], Huang et al. [26], and Ye et al. [4], $\eta$ can be expressed as follows:

$$
\begin{aligned}
& \eta_{1}=\frac{\Delta D_{\mathrm{hy}}}{\Delta D_{\mathrm{hp}}}, \\
& \eta_{2}=\frac{\Delta D_{\mathrm{vy}}}{\Delta D_{\mathrm{vp}}},
\end{aligned}
$$

where $\Delta D_{\mathrm{hp}}$ and $\Delta D_{\mathrm{vp}}$ are the variations in the horizontal and vertical diameters, respectively, of the straight-jointed model rings and stagger-jointed model rings and $\Delta D_{\text {hy }}$ and $\Delta D_{\mathrm{vy}}$ are the variations in the horizontal and vertical diameters, respectively, of the uniform ring.

Based on equations (6) and (7), the transverse deformation characteristics of the straight-jointed model rings and stagger-jointed model rings under the different concentrated loading conditions can be determined. The relationship between the $\eta$ values and the concentrated loads of the two types of ring models is shown in Figure 9, and the $\eta$ values of the two types of ring models are given in Table 2.

Figure 9 shows that $\eta$ decreases as the load increases when the load is less than $100 \mathrm{~N}$, and this phenomenon is more obvious for the stagger-jointed mode than for the other models. When the load is greater than $100 \mathrm{~N}, \eta$ does not change significantly with increasing load. In addition, the $\eta$ values of the straight-jointed model ring are significantly greater than those of the straight-jointed model.

As shown in Table 2, for the straight-jointed ring under concentrated loading conditions, the calculated ranges of $\eta$ are from 0.342 to 0.366 based on the horizontal diameter variation and from 0.368 to 0.403 based on the vertical diameter variation. For the stagger-jointed ring, the ranges of $\eta$ are from 0.521 to 0.658 based on the horizontal diameter variation and from 0.546 to 0.649 based on the vertical diameter variation.

4.2. Realistic Loading Pattern in Sandy Soil. The results of the nine tests under the realistic loading conditions in 


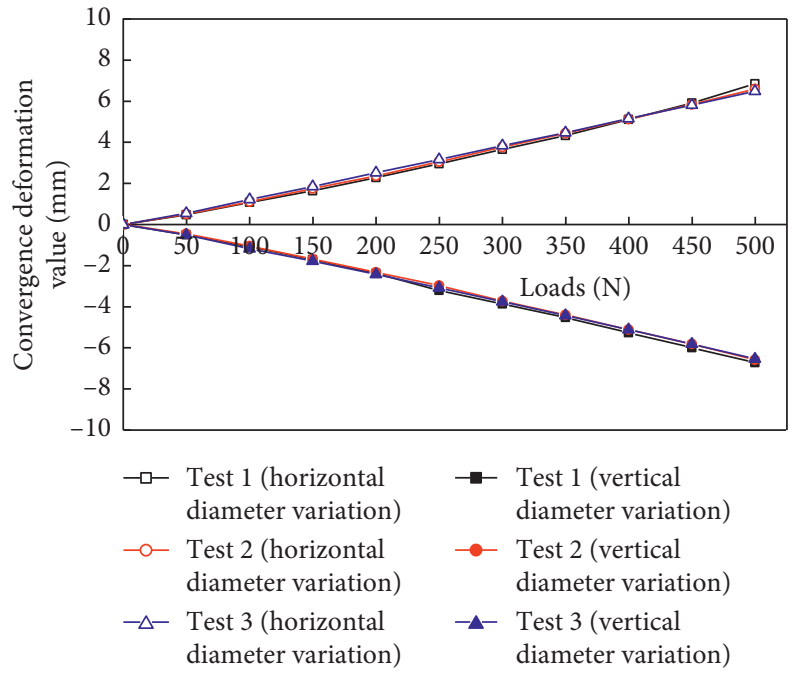

(a)

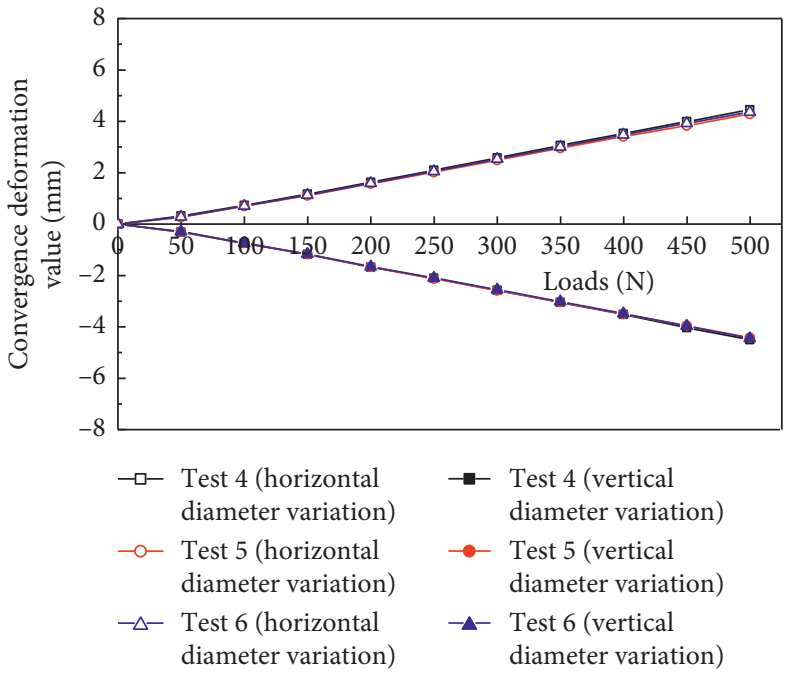

(b)

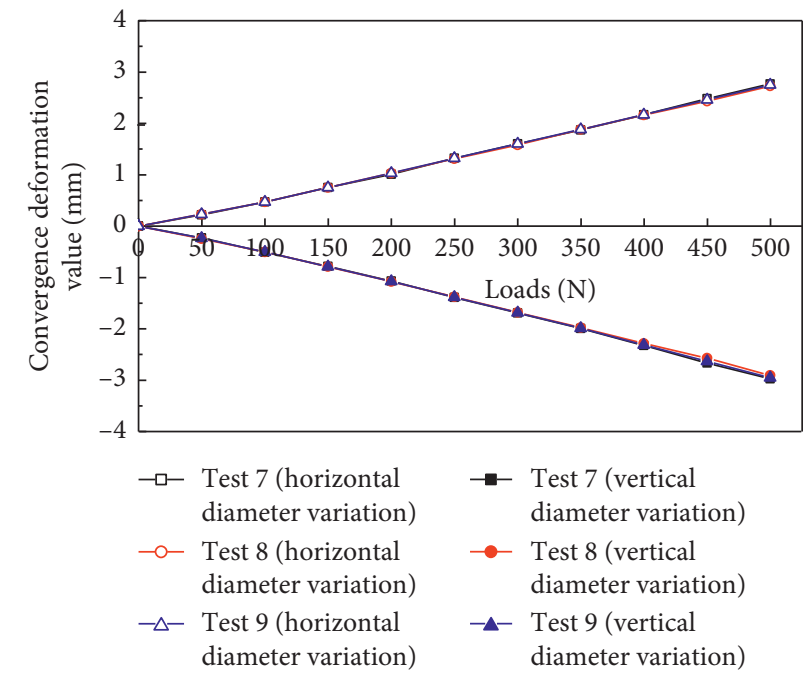

(c)

FIGURE 7: Variations in the vertical and horizontal diameters of the middle ring with increasing load for nine tests under the concentrated loading conditions. (a) Straight-jointed ring. (b) Stagger-jointed ring. (c) Uniform ring.

sandy soil (three tests for each assembly mode) are summarised in Figures 10-14 and are discussed in detail below.

\subsubsection{Soil Pressures around the Model Tunnel under the} Realistic Loading Conditions. The earth pressure values presented in this section were derived from the load cells around the tunnel circumference and along the longitudinal direction of the model tunnel crown.

For each mode, the average earth pressure values of the three repeated tests were recorded by the load cells on the model tunnel crown in the longitudinal direction, as shown in Figure 10. Figure 10 shows that the earth pressure values at the crown increase as the depth $C$ increases, and the pressure values of the different rings in each test are the same for each cover depth, which indicates that the transverse bending rigidities of the different rings are approximately equal. In addition, it can be concluded that, for all assembly modes, the earth pressure increment in a loading stage decreases when the load level becomes larger. This phenomenon is obvious under straight-jointed conditions, as can be clearly observed in Figure 11, and it can be explained by the reasons provided below. The tunnel deformation increases as the cover depth increases, and the displacement below the tunnel vault simultaneously increases. Therefore, the soil arching above the tunnel crown increases, which causes a greater load to act on the crown of the adjacent soil. Thus, the increase in the earth pressure on the tunnel crown in a loading stage decreases with increasing cover depth.

Figure 11 shows the average soil pressures acting on different ring crowns with respect to the cover depth. The theoretical vertical soil pressure at the depth of the tunnel crown calculated based on the soil weight is also shown. The results show that the slopes gradually decrease during the 


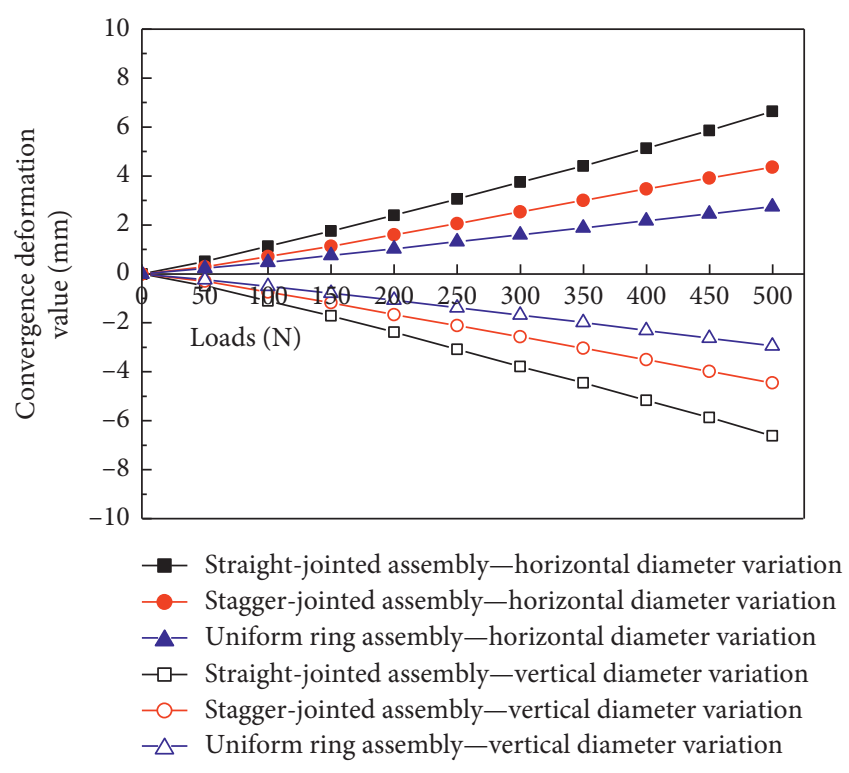

FIGURE 8: Average variations in diameter of the three repeated tests for each assembly mode under the concentrated loading conditions.

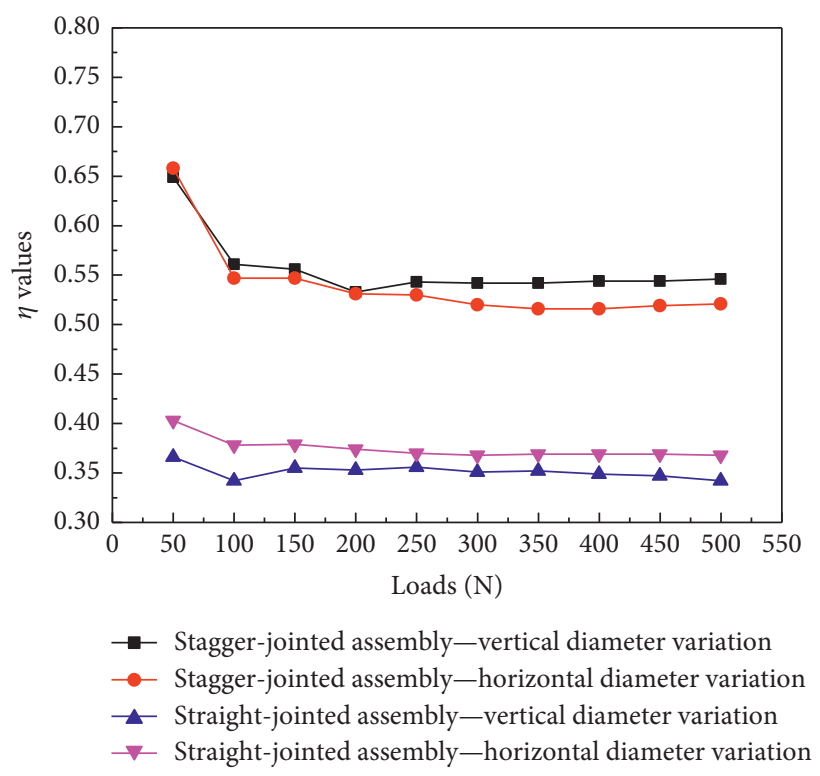

FIGURE 9: Relationships between the $\eta$ values and the loads under the concentrated loading conditions.

loading process. When the cover depth exceeds $1.0 D$ (the diameter of the model tunnel), the soil pressure acting on the uniform ring is larger than that of the other assembly modes, and the pressure acting on the straight-jointed ring is the smallest. The largest relative difference in the soil pressure between the straight-jointed model tunnel and the uniform model tunnel is $13 \%$. The difference in the earth pressure increases for these tight modes due to the variations in the transverse bending rigidities. When the transverse bending rigidity is small, such as for the straight-jointed ring, the vertical displacement of the tunnel vault will be large; thus, the arching effect will be intense and able to control the increase in the earth pressure.

As discussed above, at the same tunnel cover depth, the vertical soil pressures acting on the model tunnel crown vary by the assembly mode; therefore, we compared the effective bending rigidity ratios $\eta$ of the various assembly modes at the same cover depth instead of the same earth pressure acting on the top of the model tunnel.

The soil pressures around the circumference of the tenth ring for the different assembly modes are shown in Figure 12. The arth pressures at different positions around the circumference of the tunnel ring all increase with increasing cover depth. The pressure acting on the tunnel invert is the greatest, and the earth pressure acting on the vault is the smallest. Taking the tunnel's vertical axis as the symmetry axis, the pressures around the circumference are generally similar. The earth pressure increments during each loading time at different locations on the circumference all decrease with increasing load, which are the same as those on the crown.

4.2.2. Transverse Deformation Characteristics under the Realistic Loading Conditions. Figure 13 shows the relationships between the vertical and horizontal diameter variations of the ninth ring and the cover depth under the realistic loading conditions. The results show that the tests were repeatable.

The average diameter variations of the three repeated tests for each assembly mode are shown in Figure 14. The changes in the diameters increase with increases in the $C / D$ ratio during the entire loading process, but the rates of increase gradually decrease, which primarily occurs because the arching effect increases with the increasing $C / D$ ratio, as discussed in the previous section. Similar to the concentrated loading pattern, the rates of increase of the different assembly modes vary significantly.

4.2.3. The Value of $\eta$ under the Realistic Loading Conditions. When the distribution of the load acting on the shield lining is the same as that in Figure 2 [19], the variation in the horizontal diameter $\Delta D$ can be calculated as follows (JSCE [19]):

$$
\Delta D=\frac{\left(2 P+\pi g-q_{1}-q_{2}\right) \cdot R^{4}}{24\left(\eta \mathrm{EI}+0.0454 k_{s} R^{4}\right)},
$$

where $k_{s}$ is the resistance coefficient of the ground.

The resistance coefficient $k_{s}$ of the sand in the test is very small; therefore, this coefficient can be neglected in the calculation. In addition, based on the study by Lee and $\mathrm{Ge}$ [20], the variation in the horizontal diameter $\Delta D$ for the tunnel ring is negative. Therefore, equations (6) and (7) can be used to calculate the $\eta$ values of the rings of the straightjointed mode and the stagger-jointed mode under different load levels, as shown in Figure 15. The ranges of the $\eta$ values are given in Table 2.

Figure 15 shows that the $\eta$ values generally increase as the cover depth increases, with the exception of certain 
TABLE 2: Values of $\eta$ based on the concentrated loading pattern and realistic loading pattern.

\begin{tabular}{|c|c|c|c|c|}
\hline \multirow[b]{2}{*}{ Types } & \multicolumn{2}{|c|}{ Concentrated loading pattern } & \multicolumn{2}{|c|}{ Realistic loading pattern } \\
\hline & $\begin{array}{l}\text { Calculated by the vertical } \\
\text { diameter variations }\end{array}$ & $\begin{array}{c}\text { Calculated by the horizontal } \\
\text { diameter variations }\end{array}$ & $\begin{array}{l}\text { Calculated by the vertical } \\
\text { diameter variations }\end{array}$ & $\begin{array}{c}\text { Calculated by the horizontal } \\
\text { diameter variations }\end{array}$ \\
\hline $\begin{array}{l}\text { Straight- } \\
\text { jointed }\end{array}$ & $0.368-0.403$ & $0.342-0.366$ & $0.386-0.646$ & $0.423-0.672$ \\
\hline $\begin{array}{l}\text { Stagger- } \\
\text { jointed }\end{array}$ & $0.546-0.649$ & $0.521-0.658$ & $0.618-0.729$ & $0.587-0.761$ \\
\hline
\end{tabular}

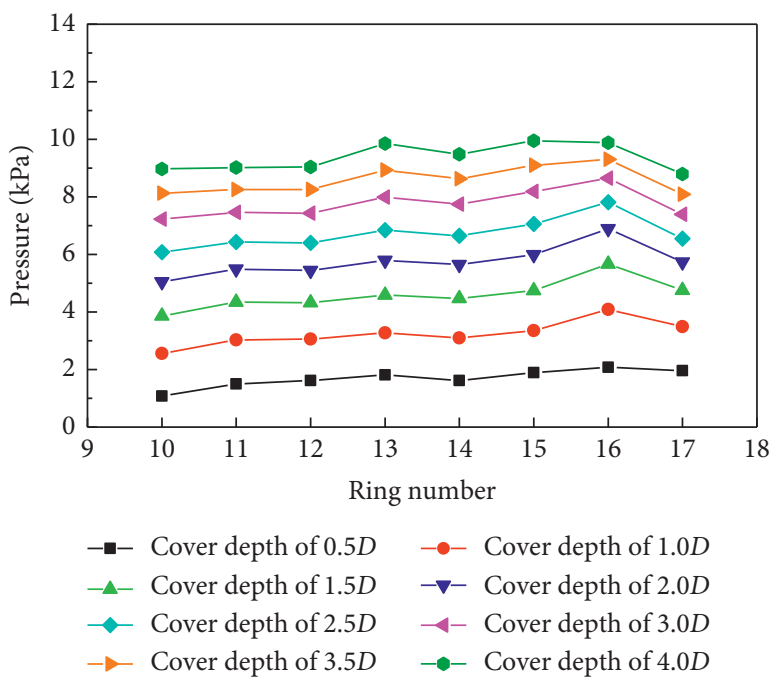

(a)

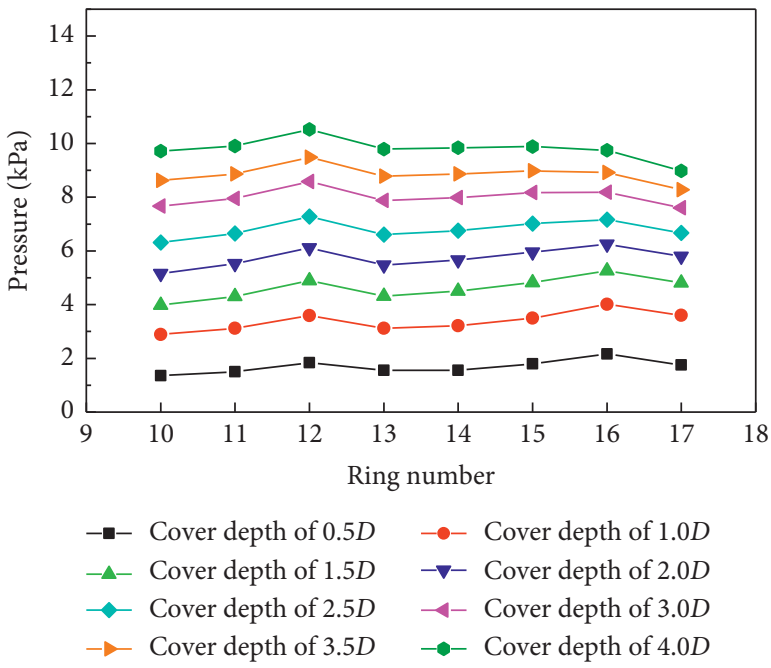

(b)

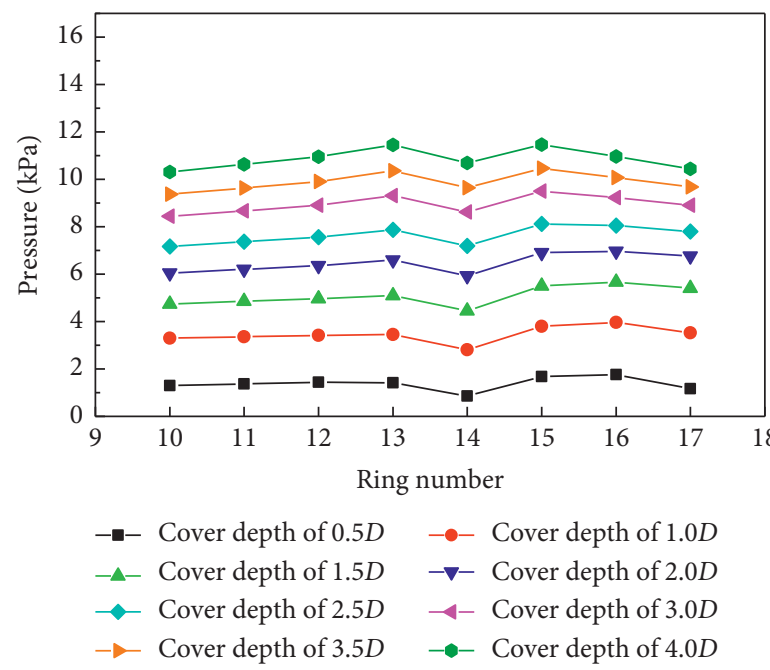

(c)

FIGURE 10: Earth pressures acting on the tunnel crowns of different rings under the realistic loading conditions. (a) Straight-jointed ring. (b) Stagger-jointed ring. (c) Uniform ring.

points, which is obvious in the straight-jointed mode. In addition, the $\eta$ values of the stagger-jointed mode are significantly greater than those of the straight-jointed mode, but the difference between them decreases with increasing cover depth.

As shown in Table 2, for the straight-jointed ring under the realistic loading pattern, the calculated range of $\eta$ is from 0.423 to 0.672 based on the variation in the horizontal diameter and from 0.386 to 0.646 based on the variation in the vertical diameter. For the stagger-jointed ring, the calculated range of $\eta$ is from 0.587 to 0.761 based on the variation in the horizontal diameter and from 0.618 to 0.729 based on the variation in the vertical diameter. 


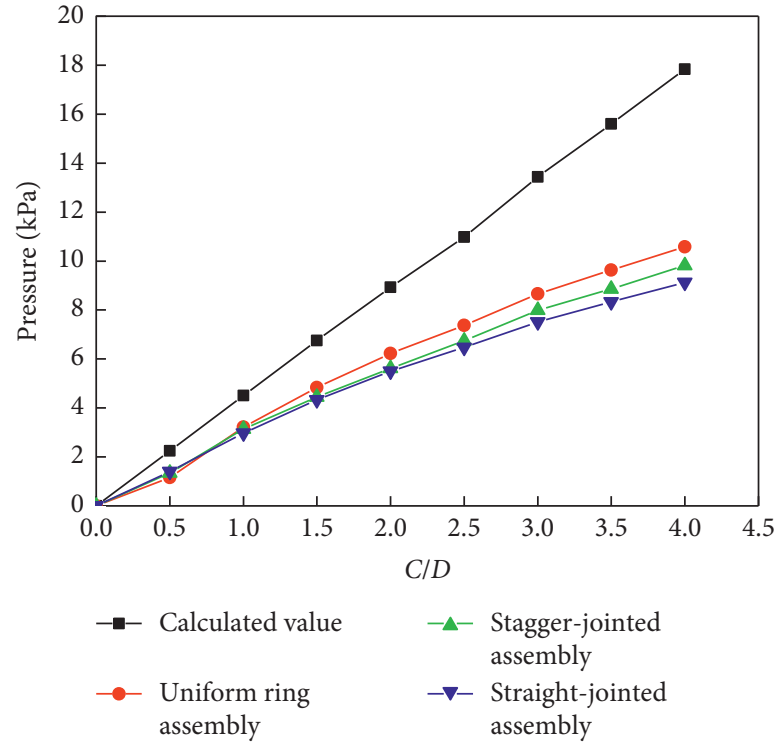

FIGURE 11: Variations in the average earth pressures acting on different ring crowns with increasing cover depth.

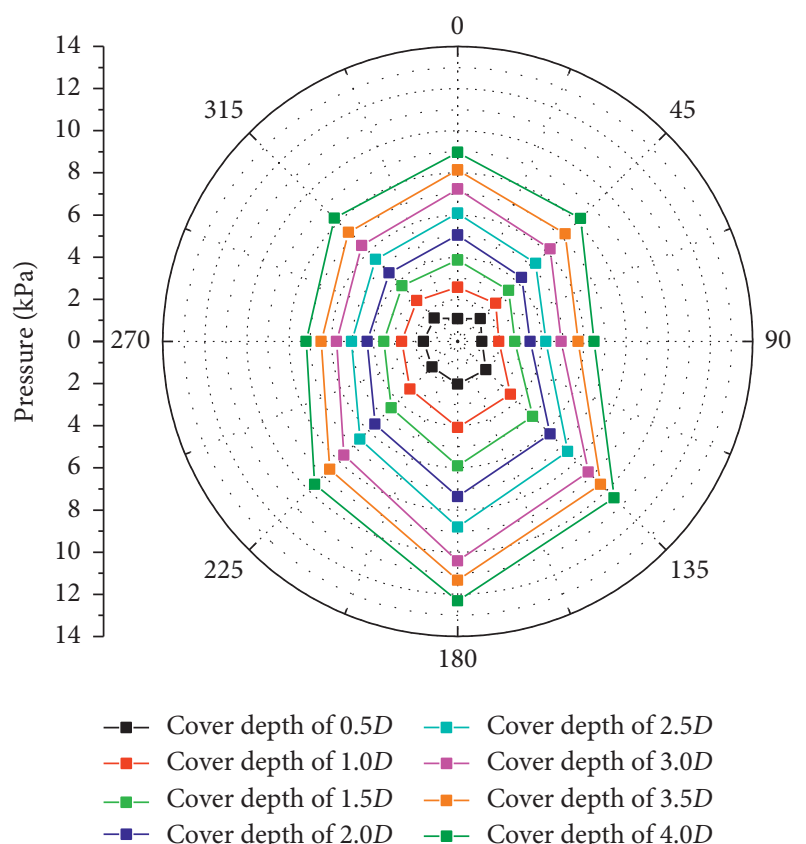

(a)

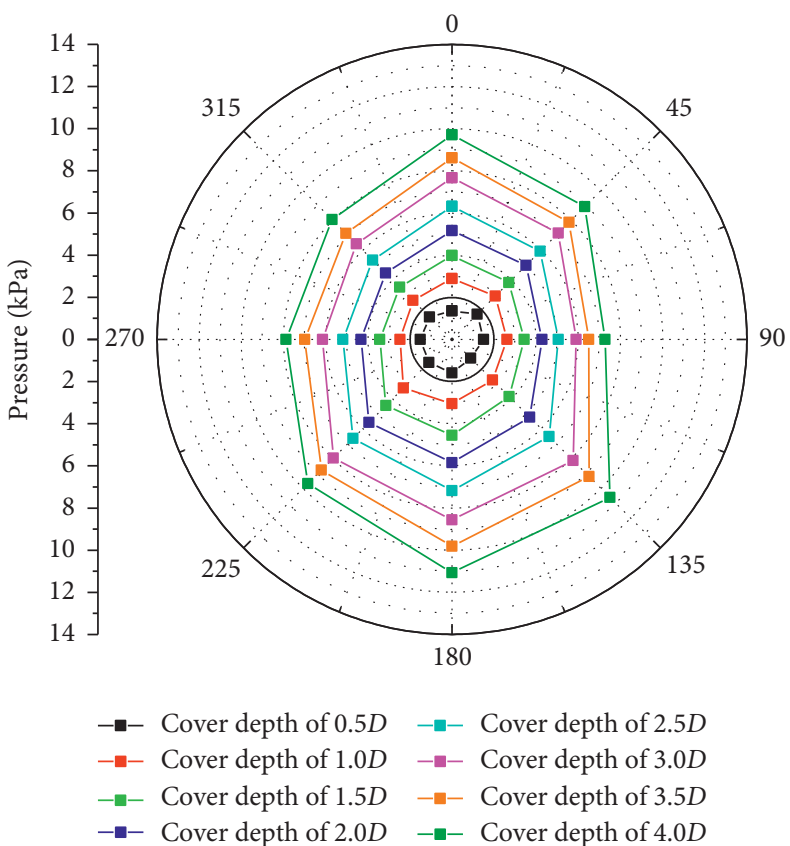

(b)

FIgURE 12: Continued. 


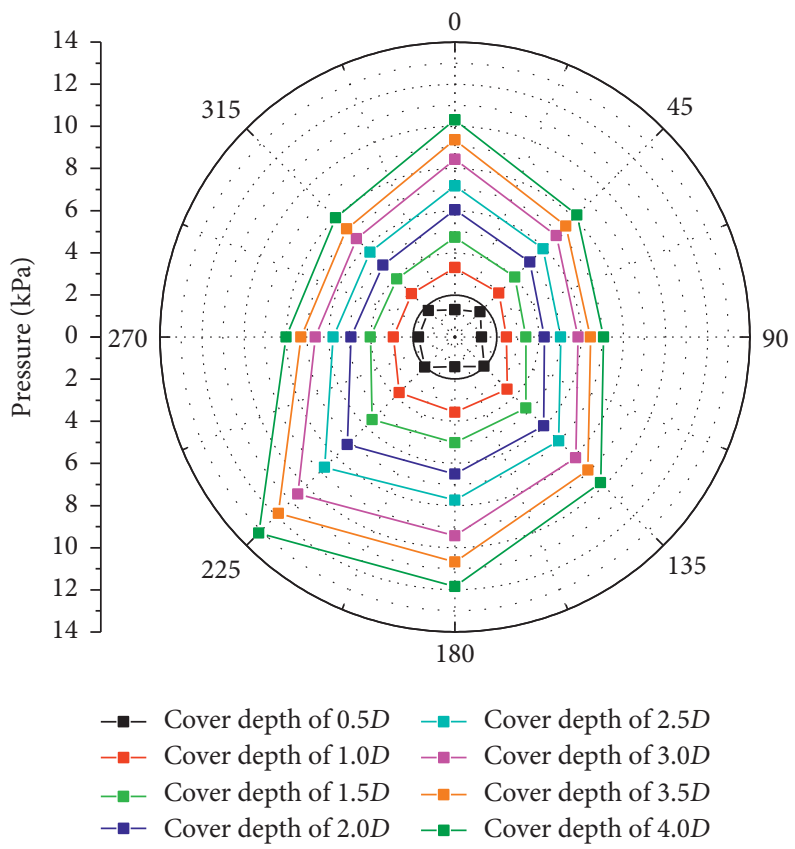

(c)

FIGURE 12: Earth pressures acting at different locations around the tunnel rings under the realistic loading conditions. (a) Straight-jointed ring. (b) Stagger-jointed ring. (c) Uniform ring.

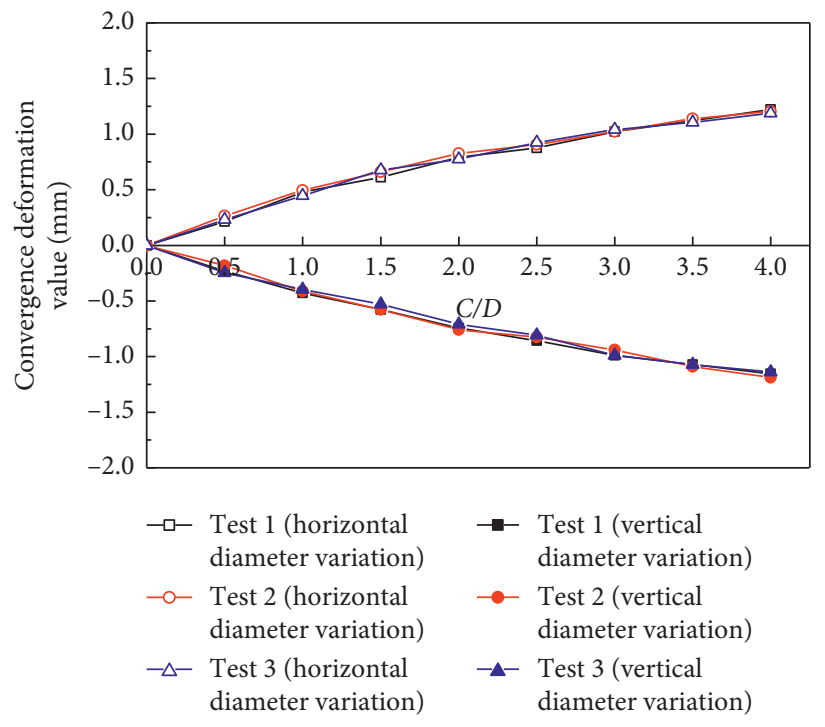

(a)

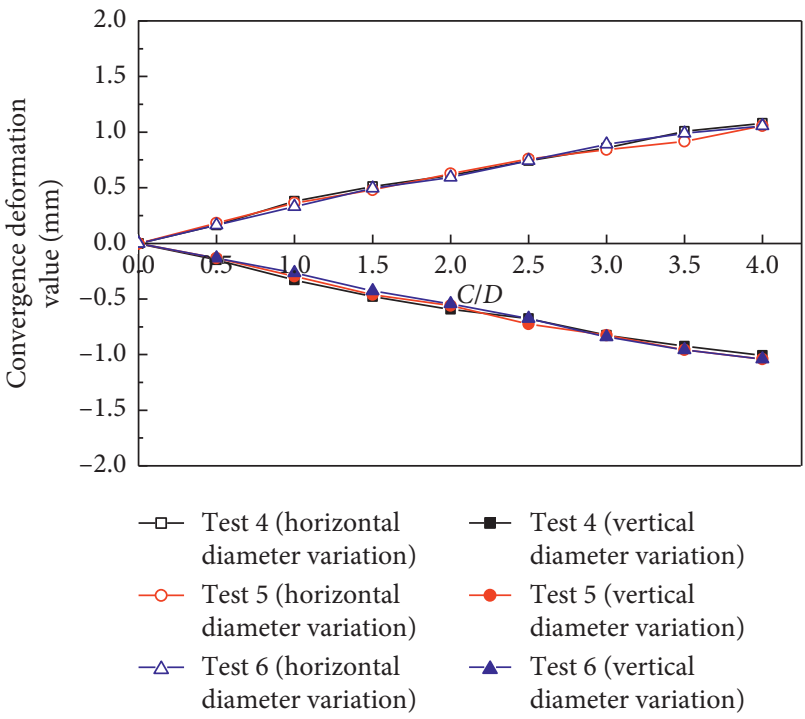

(b)

Figure 13: Continued. 


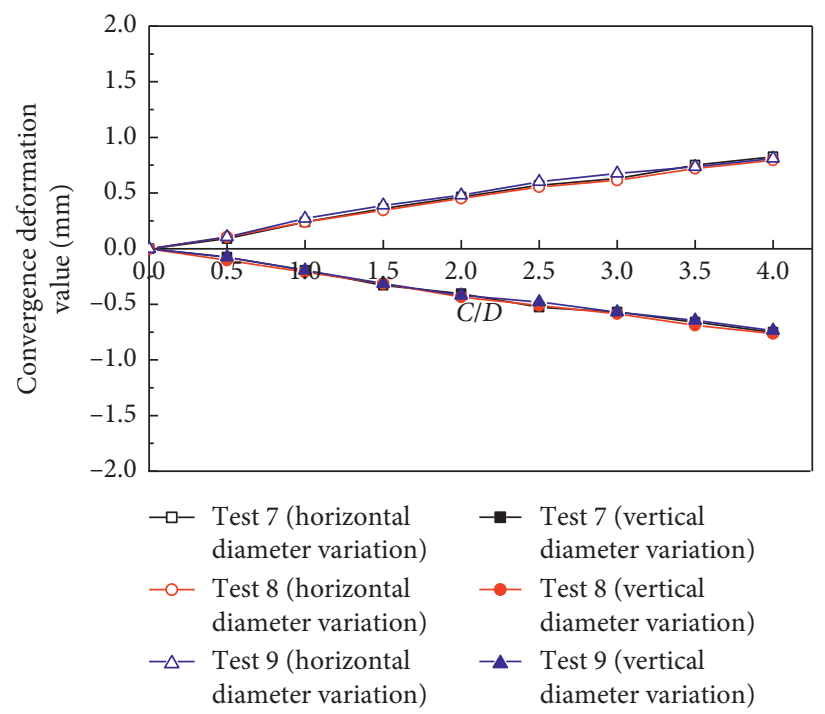

(c)

FIGURE 13: Variations in the vertical and horizontal diameters of the ninth ring with increasing load for nine tests under the realistic loading conditions. (a) Straight-jointed ring. (b) Stagger-jointed ring. (c) Uniform ring.

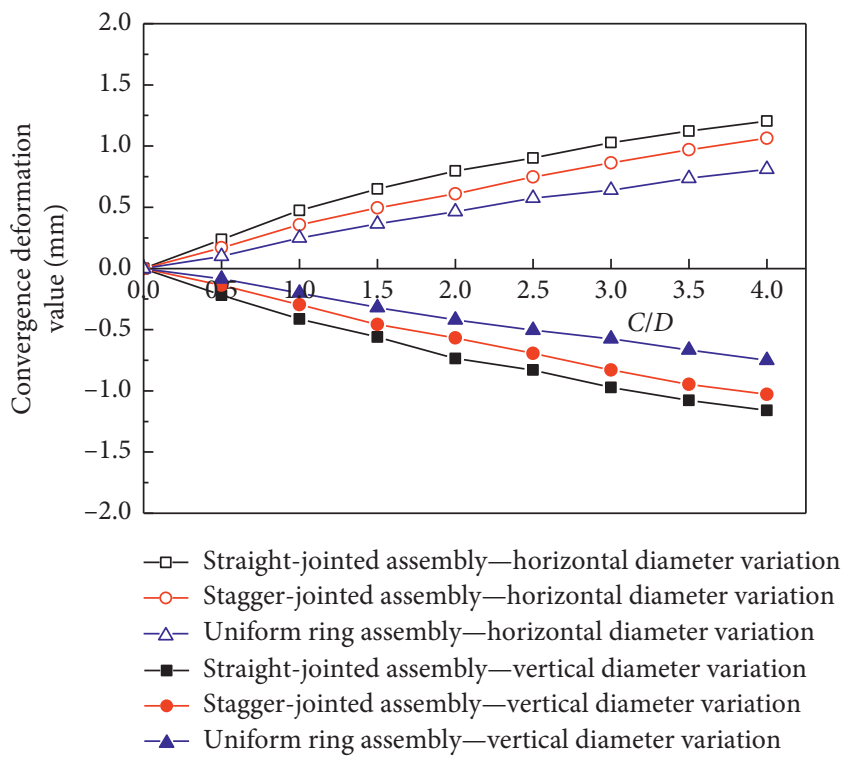

FIgURE 14: Variations in the average diameters of the three repeated tests for each assembly mode under the realistic loading conditions.

4.3. Comparison and Analysis of the Results. Figures 9 and 15 show that, under the concentrated loading conditions, when the load is small, the transverse bending rigidity efficiency values $\eta$ decrease as the load increases, whereas when the load exceeds a specific value, $\eta$ remains approximately constant. However, $\eta$ generally increases when the $C / D$ ratio increases under the realistic loading conditions. In addition, the $\eta$ values with the realistic loading pattern are larger than those with the concentrated load for the two assembly modes.

The lateral restriction of the soil around the tunnel can improve the circumferential hoop efficiency of the tunnel.

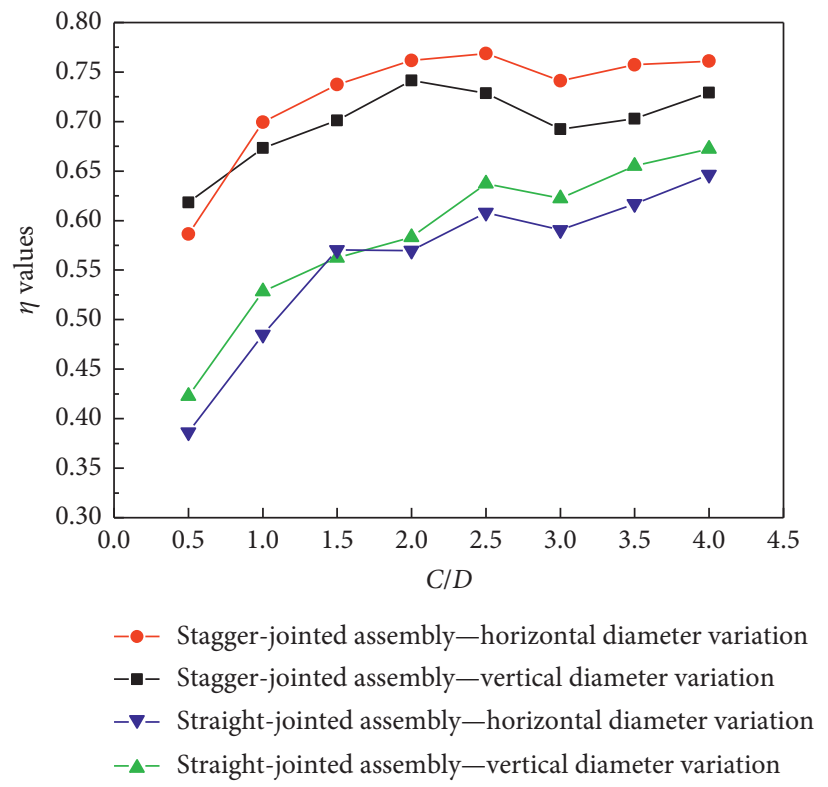

Figure 15: Relationship between the effective ratios of the transverse bending rigidity and loads under the realistic loading conditions.

This lateral restriction weakens the effects of the tunnel joints on the deformation of the tunnel by limiting the opening of the joints. Under the realistic loading pattern, the effects of the circumferential hoop increase as the cover depth increases, and the $\eta$ values also increase. Figure 15 shows that the circumferential hoop is more effective in the straightjointed model than in the other models. However, for the concentrated load, the deformation of the joint cannot be limited by the lateral restraint or the axial force. These disparities reflect the importance of the loading pattern on the $\eta$ values. 


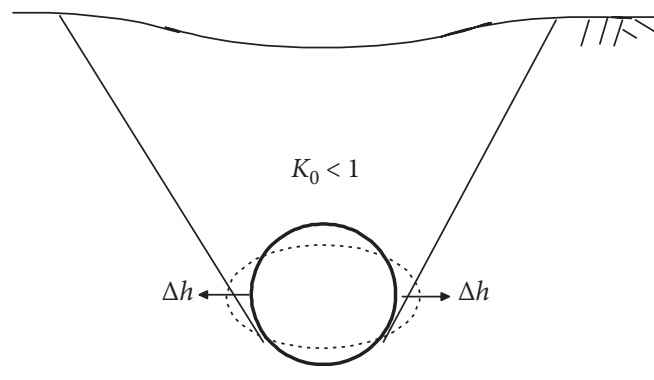

(a)

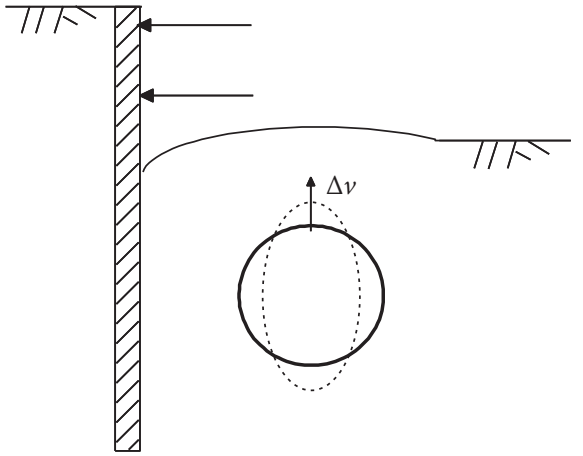

(c)

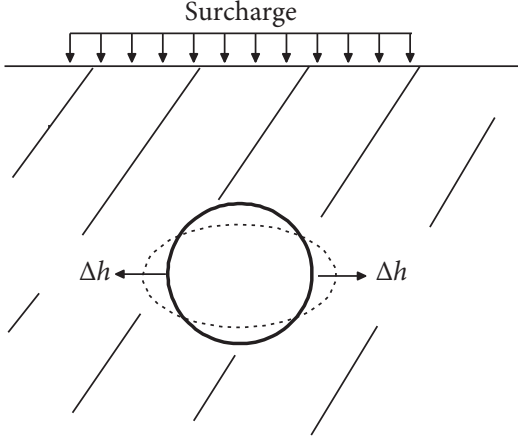

(b)

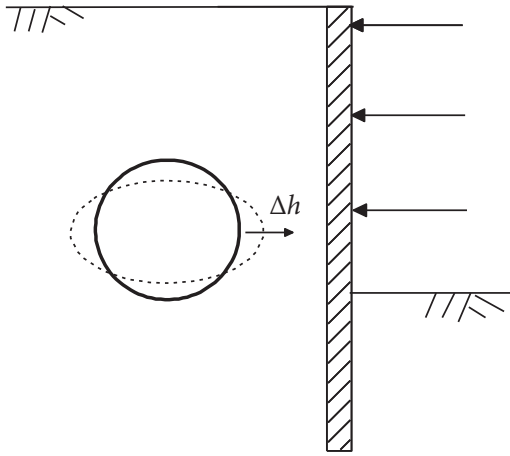

(d)

FIGURE 16: Different types of tunnelling-related problems and their associated matching criteria (Lee and Ge [20]). (a) Prediction of ground surface settlement (matching $\Delta h$ ). (b) The influence of subsequent surcharge loading on the ground surface (matching $\Delta h$ ). (c) The influence of excavation directly above an existing tunnel (matching $\Delta v$ ). (d) The influence of excavation adjacent to an existing tunnel (matching $\Delta h$ ).

TABLE 3: Values of $\eta$ obtained in this paper and previous studies.

\begin{tabular}{lccc}
\hline Source & & $\eta$ & \\
& Straight-jointed & Stagger-jointed & Notes \\
\hline Lee and Ge [20] & $0.1-0.6$ & - & In soft ground \\
Zhong et al. [21] & - & $0.4-0.8$ & $\zeta=0.3$ \\
JSCE [19] & 0.8 & 0.8 & Calculated \\
Xu [25] and Huang et al. [26] & 0.67 & $0.75-0.80$ & Under a concentrated load \\
Ye et al. [4] & $0.09-0.23$ & $0.52-0.66$ & Under a concentrated load \\
This study & $0.34-0.37$ & $0.59-0.76$ & Under a concentrated load \\
& $0.42-0.67$ & Under realistic loading conditions \\
\hline
\end{tabular}

Lee and Ge [20] suggested that, if construction activities or the existence of a heavy vertical overload lead to "squashing" of the tunnel in the lateral direction, as shown in Figures 16(a), 16(b), and 16(d), then the corresponding influence could be reflected in the variation in the horizontal diameter of the tunnel $(\Delta h)$. In addition, if construction activities reduce the soil pressure, then the corresponding influence could be reflected in the variation in the vertical diameter of the tunnel $(\Delta v)$. Therefore, the $\eta$ value should be based on the variation in the horizontal diameter.

The $\eta$ values of the segmental ring models determined in this paper (calculated based on the horizontal diameter variations) and those found in previous studies are summarised in Table 3. The differences in these results are important.

For the stagger-jointed model, the $\eta$ range obtained for the realistic loading pattern in this paper is within the ranges reported by Zhong et al. [3] and Ye et al. [4] and includes the values suggested by $\mathrm{Xu}$ [25] and Huang et al. [26]. For the straight-jointed model, the $\eta$ range determined under the realistic loading pattern in this paper is also similar to the results of Lee and Ge [20], Xu [25], and Huang et al. [26].

A logarithmic curve is used to fit the variations in the $\eta$ values with the cover depth, as shown in Figure 17. The $\eta$ values of the stagger-jointed mode and the straight-jointed mode in relation to the $C / D$ ratio can be calculated by equations (9) and (10), respectively: 


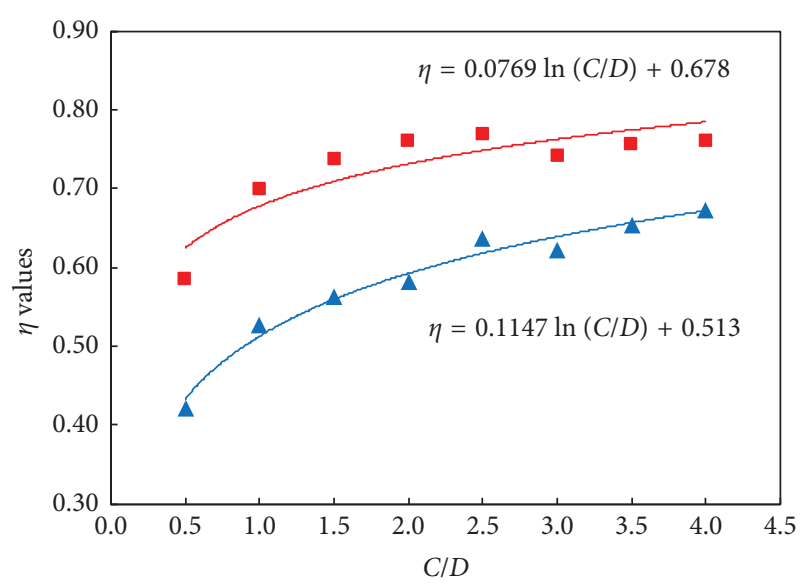

- Stagger-jointed assembly

A Straight-jointed assembly

Figure 17: Logarithmic curves between the $\eta$ values and the loads based on the realistic loading pattern.

TABLE 4: Values of $\eta$ calculated based on the formulas proposed in this paper.

\begin{tabular}{lcccccc}
\hline \multirow{2}{*}{ Types } & 1 & 2 & 3 & 4 & 5 & 6 \\
\hline Straight-jointed & 0.53 & 0.59 & 0.64 & 0.67 & 0.70 & 0.72 \\
Stagger-jointed & 0.68 & 0.73 & 0.76 & 0.78 & 0.80 & 0.82 \\
\hline \multicolumn{7}{c}{} \\
$\qquad \begin{array}{ll} \\
\end{array}$ \\
& $\eta=0.0769 \ln \left(\frac{C}{D}\right)+0.678$, \\
&
\end{tabular}

where $C$ is the cover depth of the tunnel crown and $D$ is the outside diameter of the tunnel.

Several results calculated using equations (9) and (10) are presented in Table 4 . The value of $\eta$ is related to the $C / D$ ratio. Although the formula fit is not perfect, the formula is useful and valuable for engineering designers and scientific researchers.

\section{Conclusions}

Experimental investigations were performed to analyse the effective bending rigidity ratio $\eta$ under concentrated loading conditions on an experimental bench and under realistic loading conditions in sandy soil, and the conclusions are discussed below:

(1) Using similarity theory, the similarity relationship of the joint was determined in detail based on the profile and the deformation features of the joint while bearing a load. In addition, the pretightening force of the longitudinal joint bolt was applied using a special device.

(2) Under the concentrated loading conditions, as the load increases, the variations in the diameters increase linearly during the entire loading process. Under the realistic loading conditions, the rates of increase of the diameter variations gradually decrease as the $C / D$ ratio increases, primarily because the arching effect becomes larger when the $C / D$ ratio increases.

(3) Under the concentrated loading conditions, when the load is small, the $\eta$ value decreases as the load increases; in contrast, when the load is larger than a certain value, the $\eta$ values remain approximately constant. However, under the realistic loading conditions, the $\eta$ values generally increase as the $C / D$ ratio increases. In addition, the $\eta$ values from the realistic loading pattern are greater than those under the concentrated load for both assembly modes.

(4) The reason for the previous conclusion is that the lateral control of the soil around the tunnel can improve the circumferential hoop effect of the tunnel, which can control the opening of the joints, especially for the straight-jointed model. As the cover depth increases, the effect of the circumferential hoop increases and the $\eta$ value increases.

(5) The true loading pattern is meaningful, and the corresponding $\eta$ values can thus be used for applications in real engineering. Based on the changes in the horizontal diameter, the $\eta$ values range from 0.423 to 0.672 for the straight-jointed mode and from 0.587 to 0.761 for the stagger-jointed mode. The principles of the relationships between the $\eta$ values of the different assembly modes and the $C / D$ ratio are proposed.

\section{Data Availability}

The data used to support the findings of this study are available from the corresponding author upon request.

\section{Conflicts of Interest}

The authors declare that they have no conflicts of interest.

\section{Acknowledgments}

This study was supported by the National Key Research and Development Program of China under grant no. 2017YFC0805407, the National Natural Science Foundation of China under grant no. 41630641, and the Natural Science Foundation of Tianjin City under grant no. 18JCQNJC07900.

\section{References}

[1] K. M. Lee, X. Y. Hou, X. W. Ge, and Y. Tang, "An analytical solution for a jointed shield-driven tunnel lining," International Journal for Numerical and Analytical Methods in Geomechanics, vol. 25, no. 4, pp. 365-390, 2001.

[2] WGN, \& Association IT, "Guidelines for the design of shield tunnel lining," Tunneling \& Underground Space Technology, vol. 15, no. 3, pp. 303-331, 2000. 
[3] X. Zhong, Z. Wei, Z. Huang, and Y. Han, "Effect of joint structure on joint stiffness for shield tunnel lining," Tunnelling \& Underground Space Technology, vol. 21, no. 3-4, pp. 407-408, 2006.

[4] F. Ye, C.-F. Gou, H.-D. Sun, Y.-P. Liu, Y.-X. Xia, and Z. Zhou, "Model test study on effective ratio of segment transverse bending rigidity of shield tunnel," Tunnelling and Underground Space Technology, vol. 41, no. 1, pp. 193-205, 2014.

[5] W. Q. Ding, Z. Q. Yue, L. G. Tham, H. H. Zhu, C. F. Lee, and T. Hashimoto, "Analysis of shield tunnel," International Journal for Numerical and Analytical Methods in Geomechanics, vol. 28, no. 1, pp. 57-91, 2004.

[6] H. Duddeck, "Structural design models for tunnels in soft soil in use at present in different countries," in Proceedings of the International Symposium on Weak Rock, Japan Society of Civil Engineers, Tokyo, Japan, January 1981.

[7] H. Duddeck, "Guidelines for tunnel design," Tunnels \& Tunnelling International, vol. 21, no. 12, pp. 42-44, 1989.

[8] A. Bull, "Stresses in the linings of shield-driven tunnels," Transactions of the American Society of Civil Engineers, American Society of Civil Engineers, New York, NY, USA, 1946.

[9] H. D. Morgan, "A contribution to the analysis of stress in a circular tunnel," Géotechnique, vol. 11, no. 1, pp. 37-46, 1961.

[10] R. B. Peck, A. J. Hendron, and B. Mohraz, "State of the art-soft ground tunneling," in Proceedings of the Rapid Excavation and Tunneling Conference, Chicago, IL, USA, June 1972.

[11] A. M. Muir Wood, "The circular tunnel in elastic ground," Geotechnique, vol. 25, no. 1, pp. 115-127, 1975.

[12] JSCE, The Design and Construction of Underground Structures, JSCE, Tokyo, Japan, 1977, in Japanese.

[13] Y. Koyama, "Present status and technology of shield tunneling method in Japan," Tunnelling and Underground Space Technology, vol. 18, no. 2-3, pp. 145-159, 2003.

[14] Y. Tang, The Mechanism Study of the Staggering Assembly of Shield-Driven Tunnel, M. Phil. thesis, Dept. of Geotechnics, Tongji University, Shanghai, China, 1988, in Chinese.

[15] J. H. Liu and X. Y. Hou, Shield-Driven Tunnels, China Railways Press, Beijing, China, 1991, in Chinese.

[16] Y. Koyama and T. Nishimura, The Design of Lining Segment of Shield Tunnel Using a Spring Model with Two Ring Beams, Railway Technical Research Institute, Tokyo, Japan, 1997.

[17] X. Hu, Z. Zhang, and L. Teng, "An analytical method for internal forces in DOT shield-driven tunnel," Tunnelling and Underground Space Technology, vol. 24, no. 6, pp. 675-688, 2009.

[18] Y. Koyama, "Study on the improvement of design method of segments for shield-driven tunnels," RTRI Report: Special, no. 33, RTRI, Tokyo, Japan, 2000.

[19] JSCE, Japanese Standard for Shield Tunneling, China Construction Industry Press, Beijing, China, 2001, in Chinese.

[20] K. M. Lee and X. W. Ge, "The equivalence of a jointed shielddriven tunnel lining to a continuous ring structure," Canadian Geotechnical Journal, vol. 38, no. 3, pp. 461-483, 2001.

[21] X. C. Zhong, W. Zhu, and Y. P. Ji, "The method to confirm the effective bending stiffness of shield-driven tunnel lining," Geology and Prospecting, vol. 39, pp. 185-189, 2003.

[22] K. Uchida, Design and engineering of large bore slurry shieldtunnel lining system for Trans-okyo Bay Highway, vol. 30, Civil Engineering in Japan, Tokyo, Japan, 1991.

[23] Y. Kashima, N. Kondo, and M. Inoue, "Development and application of the DPLEX shield method: results of experiments using shield and segment models and application of the method in tunnel construction," Tunnelling and Underground Space Technology, vol. 11, no. 1, pp. 45-50, 1996.
[24] K. Feng, C. He, and S. L. Xia, "Prototype tests on effective bending rigidity ratios of segmental lining structure for shield tunnel with large cross-section," Chinese Journal of Geotechnical Engineering, vol. 33, no. 11, pp. 1750-1758, 2011.

[25] L. Xu, "Study on the longitudinal settlement of shield tunnel in soft soil," D.Phil. thesis, Tongji University, Shanghai, China, 2005, in Chinese.

[26] H. W. Huang, X. U. Ling, J. L. Yan et al., "Study on transverse effective rigidity ratio of shield tunnels," Chinese Journal of Geotechnical Engineering, vol. 28, no. 1, pp. 11-18, 2006.

[27] T. Xu, The Similarity Theory and the Model Test, China Agricultural Machinery Press, Beijing, China, 1982.

[28] D. W. Hobbs, "Scale model studies of strata movement around mine roadways-I the dependence of roadway closure upon rock strength," International Journal of Rock Mechanics and Mining Sciences \& Geomechanics Abstracts, vol. 5, no. 3, pp. 219-235, 1968.

[29] S. W. Jeon, C. W. Hong, J. W. Kim, and Y. K. Kim, "Effect of a karstic lime cavern on the stability of tunnel-a scaled model test," Journal of the Korean Society for Geosystem Engineering, vol. 40, pp. 147-158, 2003.

[30] J. W. Kim and J. Y. Park, "A study on the deformation behaviors around twin tunnels using scaled model tests," Journal of Korean Society for Rock Mechanics, vol. 14, no. 5, pp. 381-390, 2004.

[31] J.-W. Kim and M.-K. Kim, "A study on the stability of twin tunnels in anisotropic rocks using scaled model tests," Journal of Korean Society For Rock Mechanics, vol. 22, no. 3, pp. 205-213, 2012.

[32] S. C. Baek, B. S. Jang, T. G. Lee et al., "A study on the stability estimation procedure for reinforced pillar of twin tunnel," Journal of the Korean Geoenvironmental Society, vol. 10, no. 7, pp. 81-91, 2009.

[33] M. A. Meguid, O. Saada, M. A. Nunes, and J. Mattar, "Physical modeling of tunnels in soft ground: a review," Tunnelling \& Underground Space, vol. 23, no. 22, pp. 185-198, 2008.

[34] M. Ahmed and M. Iskander, "Analysis of tunneling-induced ground movements using transparent soil models," Journal of Geotechnical and Geoenvironmental Engineering, vol. 137, no. 5, pp. 525-535, 2011.

[35] A. A. Sonin and R. F. Probstein, "A generalization of the theorem and dimensional analysis," Proceedings of the National Academy of Sciences, vol. 101, no. 23, pp. 8525-8526, 2004.

[36] L. I. Sedov, M. Friedman, and R. E. Street, Similarity and Dimensional Methods in Mechanics, Mir Publishers, Moscow, Russia, 1982.

[37] G. Zheng, T. Cui, X. Diao, T. au, L. Zhang, and J. Ge, "Study of the collapse mechanism of shield tunnels due to the failure of segments in sandy ground," Engineering Failure Analysis, vol. 79, pp. 464-490, 2017.

[38] Z. Zhang and M. Huang, "Geotechnical influence on existing subway tunnels induced by multiline tunneling in Shanghai soft soil," Computers and Geotechnics, vol. 56, no. 3, pp. 121-132, 2014.

[39] F. Weixing, "Test research on shield tunnel of simulating the influence of voids in shield tail," Metro and Light Rail, vol. 2, pp. 38-42, 1993, in Chinese.

[40] W. H. N. C. Van Empel, R. G. A. De Waal, and C. Van der Veen, "Segmental tunnel lining behaviour in axial direction," Geotechnical Aspects of Underground Construction in Soft Ground, pp. 357-362, CRC Press, Rotterdam, Netherlands, 2000.

[41] W.-Q. Ding, Y.-C. Peng, Z.-G. Yan, B.-W. Shen, H.-H. Zhu, and X.-X. Wei, "Full-scale testing and modeling of the mechanical behavior of shield TBM tunnel joints," Structural Engineering and Mechanics, vol. 45, no. 3, pp. 337-354, 2013. 


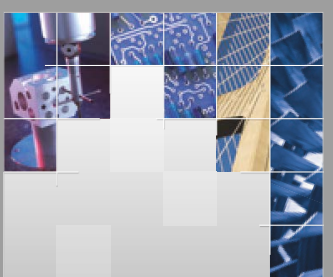

\section{Enfincering}
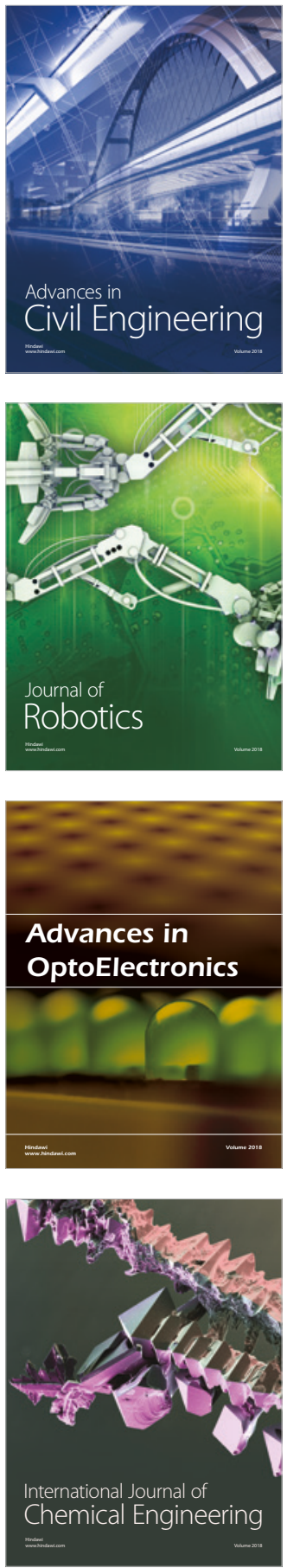

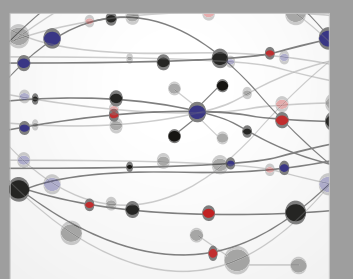

\section{Rotating \\ Machinery}

The Scientific World Journal

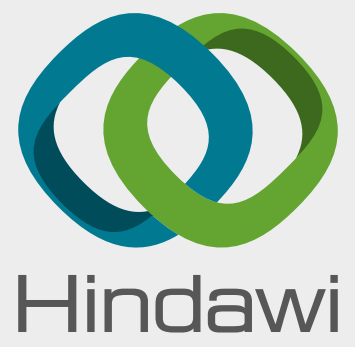

Submit your manuscripts at

www.hindawi.com
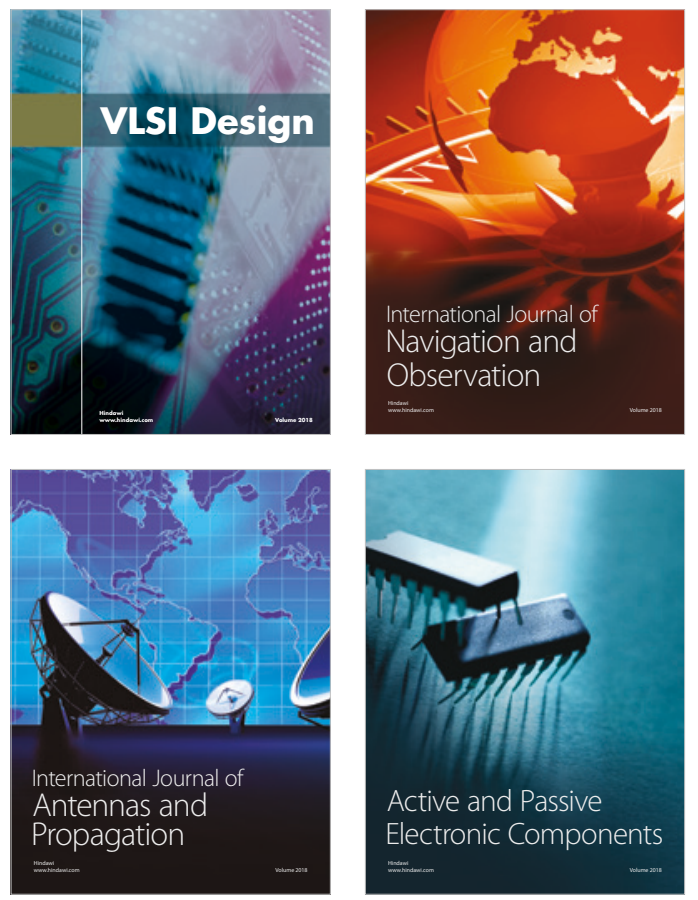
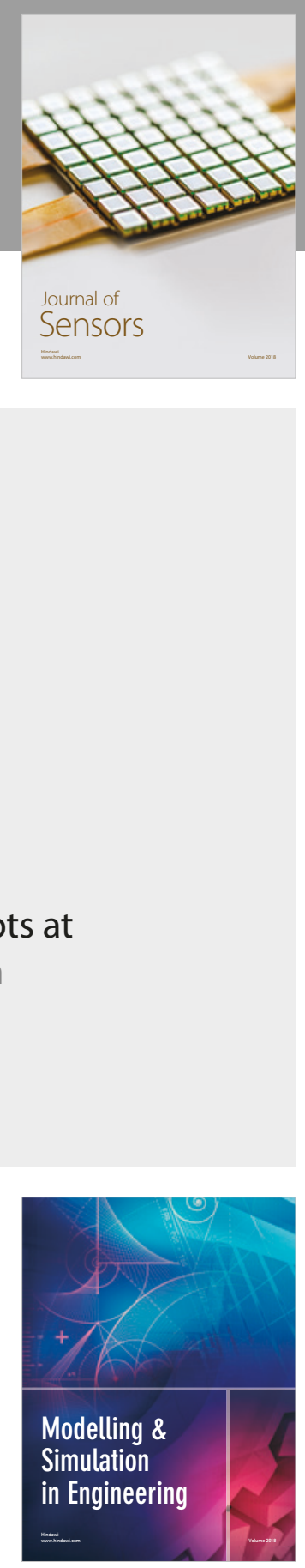

\section{Advances \\ Multimedia}
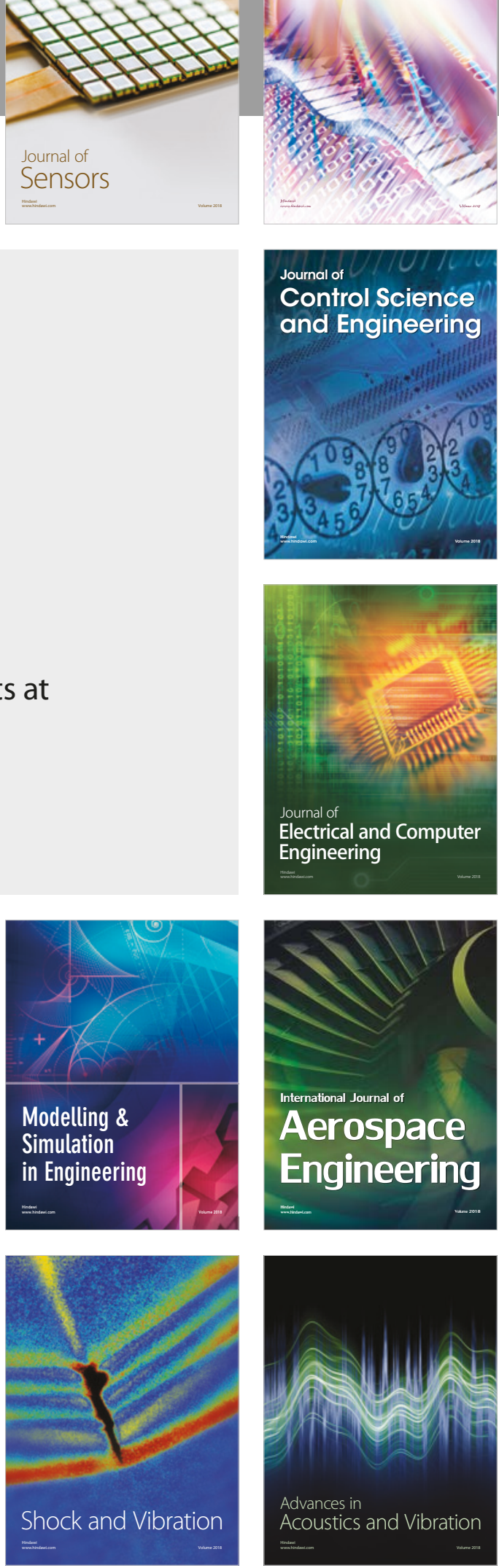